\title{
CRYSTAL STRUCTURES OF COMPOUNDS POTENTIALLY RELATED TO THE BISHOMOTROPYLIUM ION
}

\author{
M.S. Thes is Submitted to lowa State University, \\ November, 1972
}

L. K. Read

\author{
Ames Laboratory, USAEC \\ lowa State University \\ Ames, lowa 50010
}

Date of Manuscript: November, 1972

PREPARED FOR THE U. S. ATOMIC ENERGY COMMISSION DIVISION OF RESEARCH UNDER CONTRACT NO. W-7405-eng-82 


\section{DISCLAIMER}

This report was prepared as an account of work sponsored by an agency of the United States Government. Neither the United States Government nor any agency Thereof, nor any of their employees, makes any warranty, express or implied, or assumes any legal liability or responsibility for the accuracy, completeness, or usefulness of any information, apparatus, product, or process disclosed, or represents that its use would not infringe privately owned rights. Reference herein to any specific commercial product, process, or service by trade name, trademark, manufacturer, or otherwise does not necessarily constitute or imply its endorsement, recommendation, or favoring by the United States Government or any agency thereof. The views and opinions of authors expressed herein do not necessarily state or reflect those of the United States Government or any agency thereof. 


\section{DISCLAIMER}

Portions of this document may be illegible in electronic image products. Images are produced from the best available original document. 


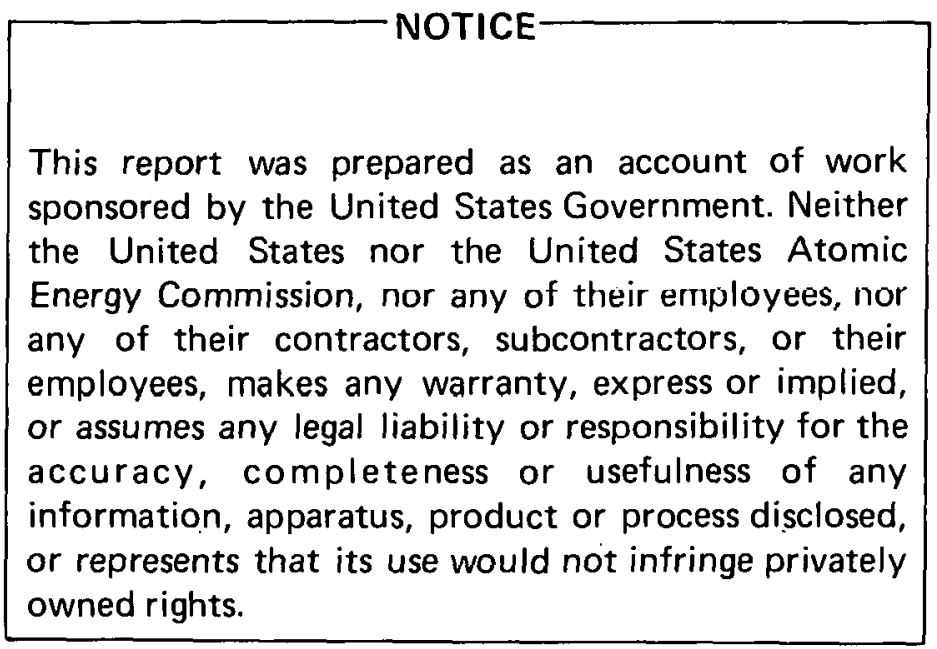

Available from: National Technical Information Service Department $A$

Springfield, VA 22151

Price: Microfiche $\$ 0.95$ 
Crystal structures of compounds potentially

related to the bishomotropylium ion

by

Leonard Kendall Read

\author{
A Thesis Submitted to the \\ Graduate Faculty in Partial Fulfillment of \\ The Requirements for the Degree of \\ MASTER OF SCIENCE \\ Department: Chemistry \\ Major: Physical Chemistry
}

Approved:

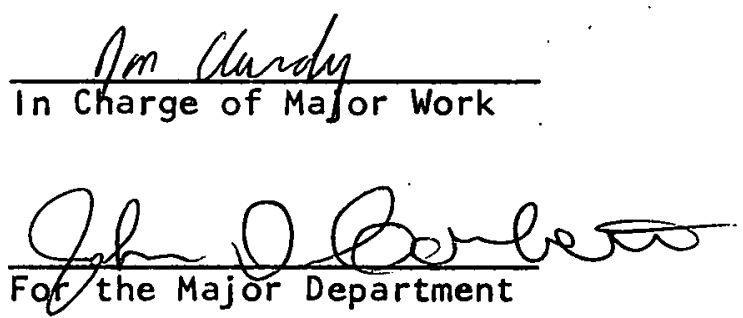

Charlitte EFodence

For the Graduate College

lowa State University

Ames, lowa 
ABSTRACT

INTRODUCT ION

HISTORICAL BACKGROUND

Pericyclic Rearrangements of cis-Bicyclo[6.1.0]-

Electrophilic Cycloadditions to cis-Bicyclo[6.1:0]-

nona-2, 4, 6-triene

THE CRYSTAL STRUCTURE OF 10,10,11,11-TETRACYANOBICYCLO[7.2.0]-

UNDECA-2, 4,7-TRIENE

Preliminary Investigation and Data Collection

Solution and Refinement

Description and Discussion of Structure

THE CRYSTAL STRUCTURE OF 6-CHLORO-10,10,11,11-TETRACYANOBICYCLO$[7.2 .0]$ UNDECA-2, 4,7-TRI ENE

Preliminary Investigation and Data Collection

Solution and Refinement

Description and Discussion of Structure

DISCUSSION OF RESULTS

45

B I BL I OGRAPHY

47

ACKNOWLEDGEMENT 
The basic interest in pericyclic addition reactions of bicyclo[6.1. $]$ nona-2,4,6-triene systems has led to the $x$-ray structure determination of two product compounds of such reactions. Upon reaction of tetracyanoethylene with bicyclo [6.1.0] nona-2,4,6-triene (1) and 9-chlorobicyclo $[6.1 .0]$ nona-2, 4,6-triene (2) compounds $\underline{3}$ and $\underline{4}$ are formed. 1
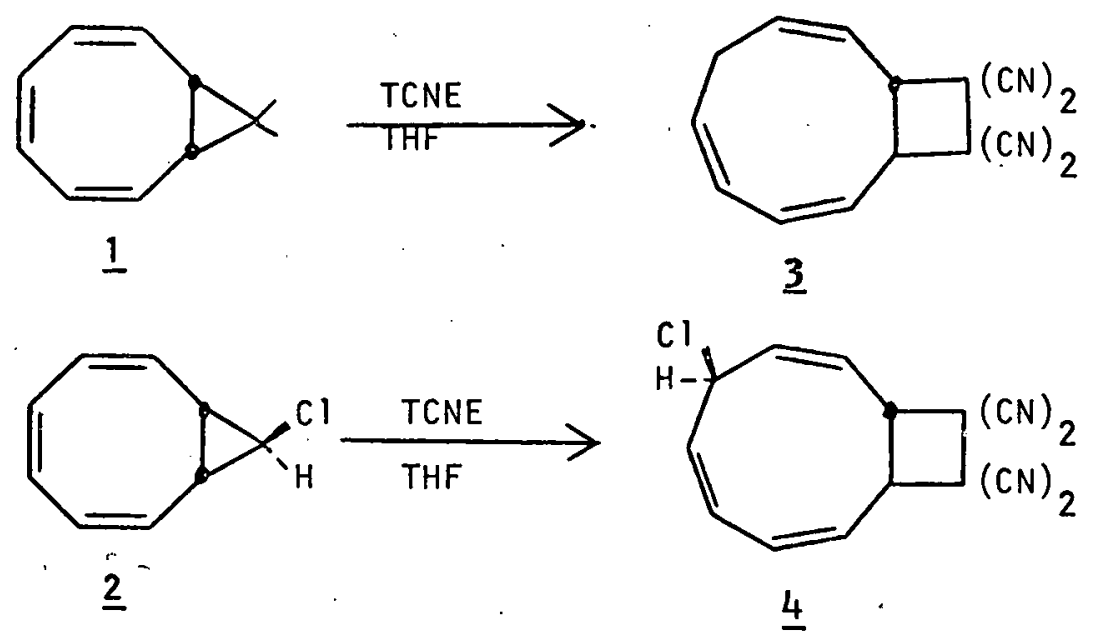

A reaction scheme has been proposed for the production of $\underline{3}$ and $\underline{4}{ }^{2}$ A severe test for any postulated reaction mechanism is the geometrical configuration of the product. Chemical and spectroscopic means of elucidating the stereochemistry had been tried to no avail; hence, $X$-ray diffraction teciniques were chosen to unambiguously resolve the geometry.

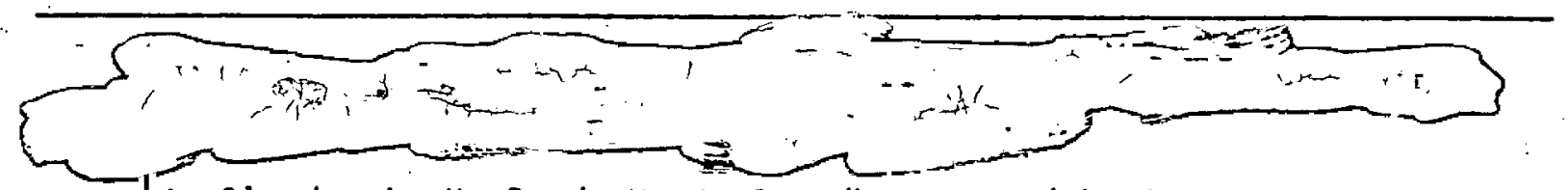

J. Clardy, L. K. Read, M. J. Broadhurst, and L. A. Paquette, J. Amer. Chem. Soc., 94, 2904 (1972).

2L. A. Paquette, M. J. Broadhurst, C. M. Lee, and J. C. Clardy, J. Amer. Chem. Soc., 94, 630 (1972). 
From the acquired knowledge of the geometry of $\underline{3}$ and $\underline{4}$, a proposed mechanistic scheme has been suggested which involves a 1,3-bishomotropylium ion. 1

Crystals of $\underline{\underline{3}}$ (kindly donated by $L$. A. Paquette) were obtained by slow evaporation of methylene chloride solution. The crystals were found to belong to the orthorhombic space group class $P_{b e n}$ with systematic extinctions for $0 k 1 \quad(k=2 n+1)$, hol $(1=2 n+1)$, and $h k 0(h+k=2 n+1)$. From cell constants of $a=15.4(1) \AA, b=6.93(1) \AA$, and $c=24.97(1) \AA$, the density was calculated to be $1.23 \mathrm{~g} / \mathrm{cm}^{3}$ with $z=8$. The final unweighted discrepancy index was calculated to be $R=8.5$ per cent for the observed data.

Crystals of 4 (kindly donated by $L$ : A. Paquette) were grown by slow evaporation from methylene chioride solution. The crystals were found to belong to the triclinic space group class $P \frac{1}{1}$. Cell constants of $a=$ $7.37(2) \AA, b=6.97(3) \AA, c=14.07(2) \&, \alpha=88.6(19, \beta=76.3(19$, and $\gamma=101.7(19$ yielded a congruent calculated and observed density of $1.36 \mathrm{~g} / \mathrm{cm}^{3}$ for $Z=2$. The final unweighted discrepancy index was calculated to be $R=8.9$ per cent for the observed data.

1J. C.lardy, L. K. Read, M. J. Broadhurst, and L. A. Paquette, J. Âmer. Chem. Soc., 24,2904 (1972). 
INTRODUCTION

In this thesis, the crystal structures of $10,10,11,11-$ tetracyanobicyclo[7.2.0]undeca-2,4,7-triene (1) and 6-chloro-10,10,11,11-tetracyanobicycio[7.2.0]undeca-2,4,7-triene (2) are reported. The interest in the geometrical configuration of the two related compounds evolves from the desire to elucidate the mechanistic scheme of their production. from cycloaddition of tetracyanoethylene to cis-bicyclo[6.1.0]nona-2,4,6triene systems. A severe test of any postulated reaction mechanism is the geometrical configuration of the product. Chemical and spectroscopic means of elucldating the stereochemistry had been tried to no avail; hence, $X$-ray diffraction techniques were chosen to unambiguously resolve the geometry. From the acquired knowledge of the geometry of $\underline{1}$ and $\underline{2}$, a proposed mechanistic scheme, which involves a 1,3-bishomotropylium ion intermediate, has been suggested.

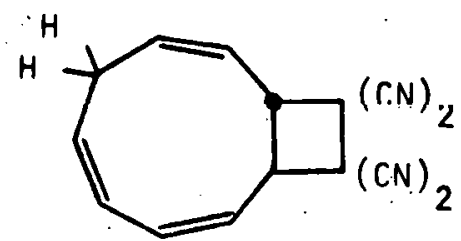

1

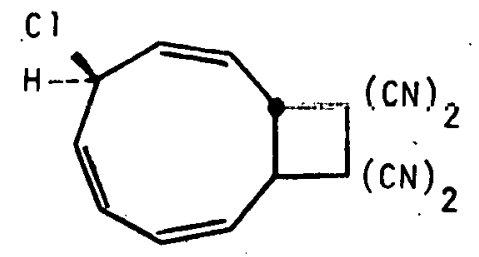

$\underline{2}$ 
HISTORICAL BACKGROUND

Pericyclic Rearrangements of cis-Bicyclo[6.1.0 ]nona-2,4,6-triene Reactions involving cis-bicyclo[6.1.0]nona-2,4,6-triene (3a, $\underline{3 b})$ have been extensively studied in the past ten years (1-5). Since the advent of orbital symmetry theory (6), thermal pericyclic rearrangements of bicyclononatriene have been of prominent interest due to the conformational flexibility of the bicyclic system. Such flexibility would lead to different alignments of the $p \pi$ orbitals in the triene segment and the cyclopropane orbitals within the fused rings ( $\underline{3 a}, \underline{3 b})$. By studying many of the intriguing thermal reactions of cis-bicyclo[6.1.0]nona-2,4,6-triene, one could then predict the mechanism involved during these various rearrangement processes.

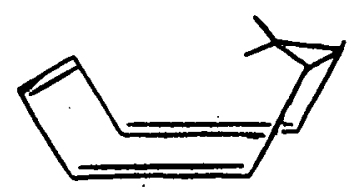

$3 a$

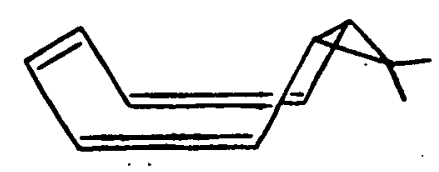

$\underline{3 b}$

The works of Vogel and Kiefer (1) showed that thermal bond relocation was possible in the bicyclononatriene system. They observed that bicyclononatriene (4) and 9,9-dichlorobicyclononatriene ()) underwent valence isomerization to yield 8,9-dihydroindene ( 6 ) and 1,2-dichloro8,9-dihydroindene (Z) (Equations 1 and 2), respectively. Equation 3, which involves a valence tautomer intermediate-tricyclo[4.3.0.0]nona2,4-diene ( $(8)$, demonstrates a possible mechanism for these reactions (2). 

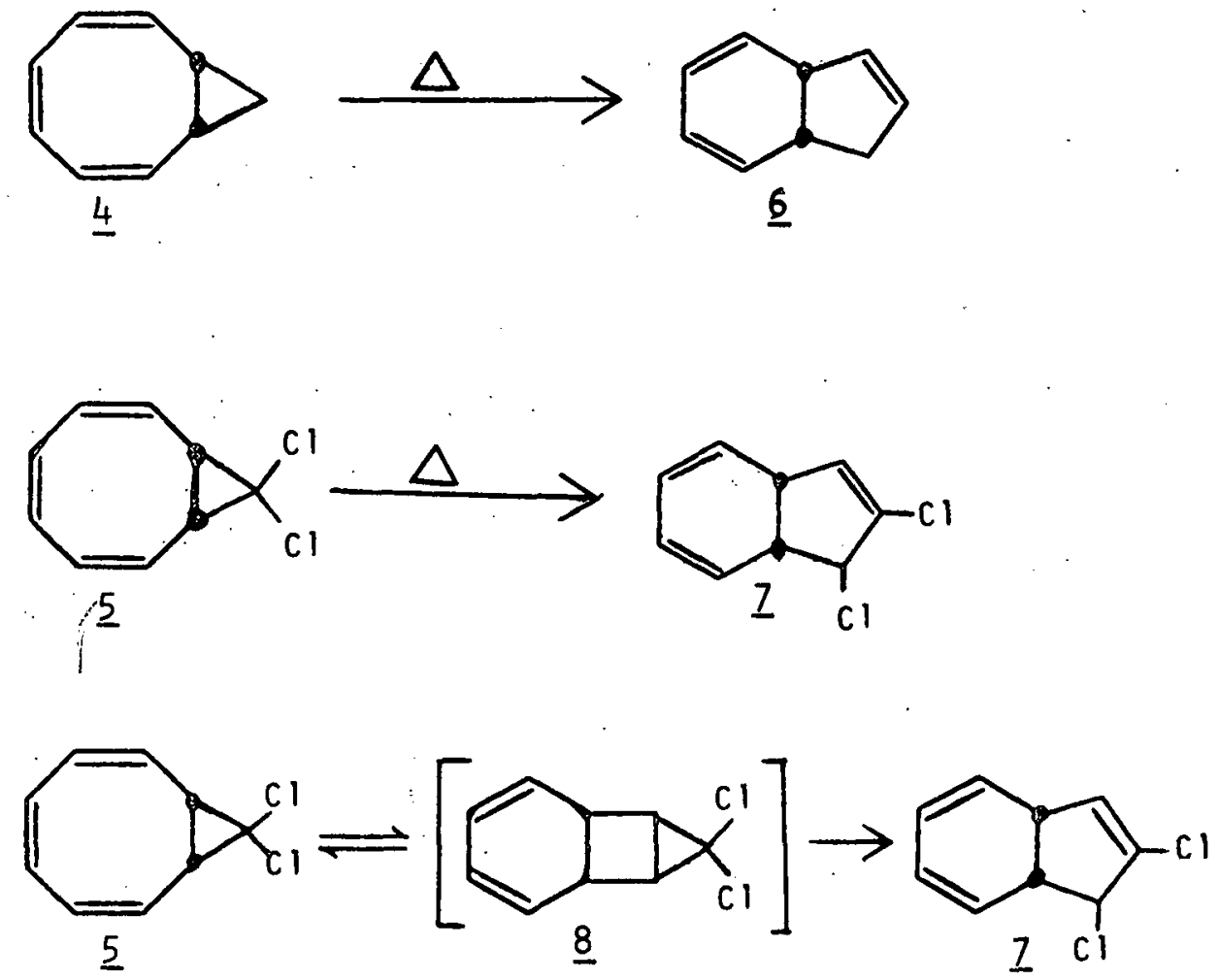

Similar experiments were performed by Katz and Garratt (3) with both anti- and syn-9-chlorobicyclo[6.1.0]nona-2,4,6-trienes (2 and 10, respectively). They discovered, upon thermal rearrangement, that both anti- and syn-9-chlorobicyclononatriene yielded the same product, 1-chloro-8,9-dihydroindene (11) (Equation 4), and suggested that the anti-9-chloro derivative followed Vogel and Kiefer's mechanistic scheme $(1,2)$.

Another mechanism for thermal rearrangement, which was inclusive for both the anti- and syn-9-chloro derivatives of bicyclononatriene, was advocated by La Lancette and Benson (4). This mechanism postulated that chlorocyclononatetraene (12) was the common intermediate since both 


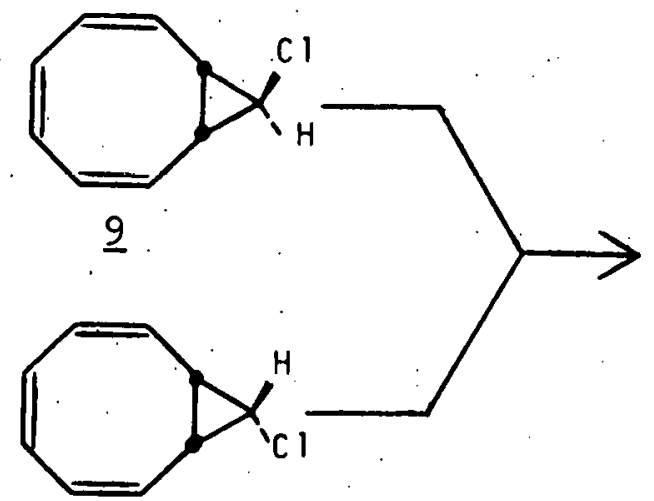<smiles>ClC1C=CC2C=CC=CC12</smiles>

11

$\underline{10}$

9-chloro derivatives gave the same product (11) (Equation 5).

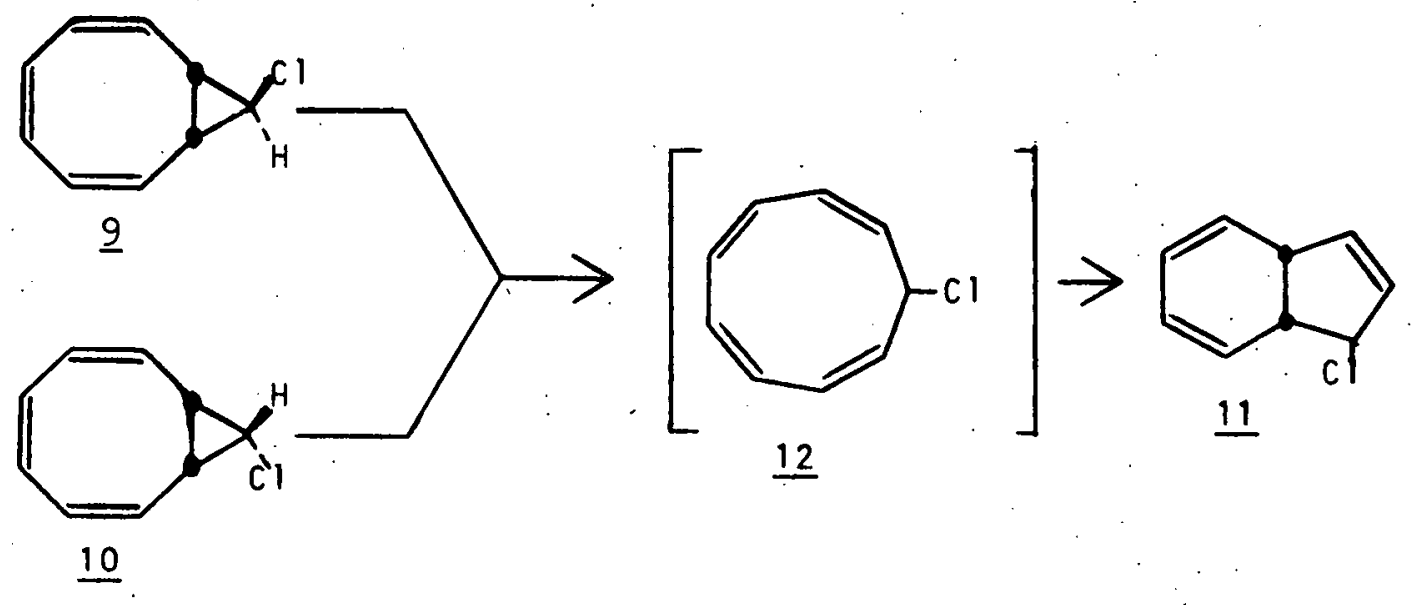

Applying the techniques of orbital symmetry theory, as illustrated by Woodward and Hoffmann (6), and the known tendency of disrotatory synbicyclocyclopropyl chloride ring opening (7) to 9-chlorobicyclononatriene, the syn-9-chloro derivative could react via the Vogel-Kiefer mechanism. In support of these conclusions, Barborak et al. (5) demonstrated that the syn-9-deuterio-9-chloro derivative of bicyclonoatriene produced, 
with known stereochemistry, exo-1-chloro-2-deuterio-cis-8,9-dihydroindene; which does indeed agree with the structure predicted by the Vogel-Kiefer mechanism (Equation 6). Such a mechanism could also be theorized for the thermal rearrangement of the 9,9-dichloro derivative. Barborak et al: also proposed that the anti-9-chloro derivative of bicyclononatriene did not react by the same mechanism as the syn derivative, but followed La Lancette and Benson's (4). theoretical scheme using the cyclononatetraene intermediate. At that time, no considerations had been given to the conformation of the cyclononatetraene intermediate.
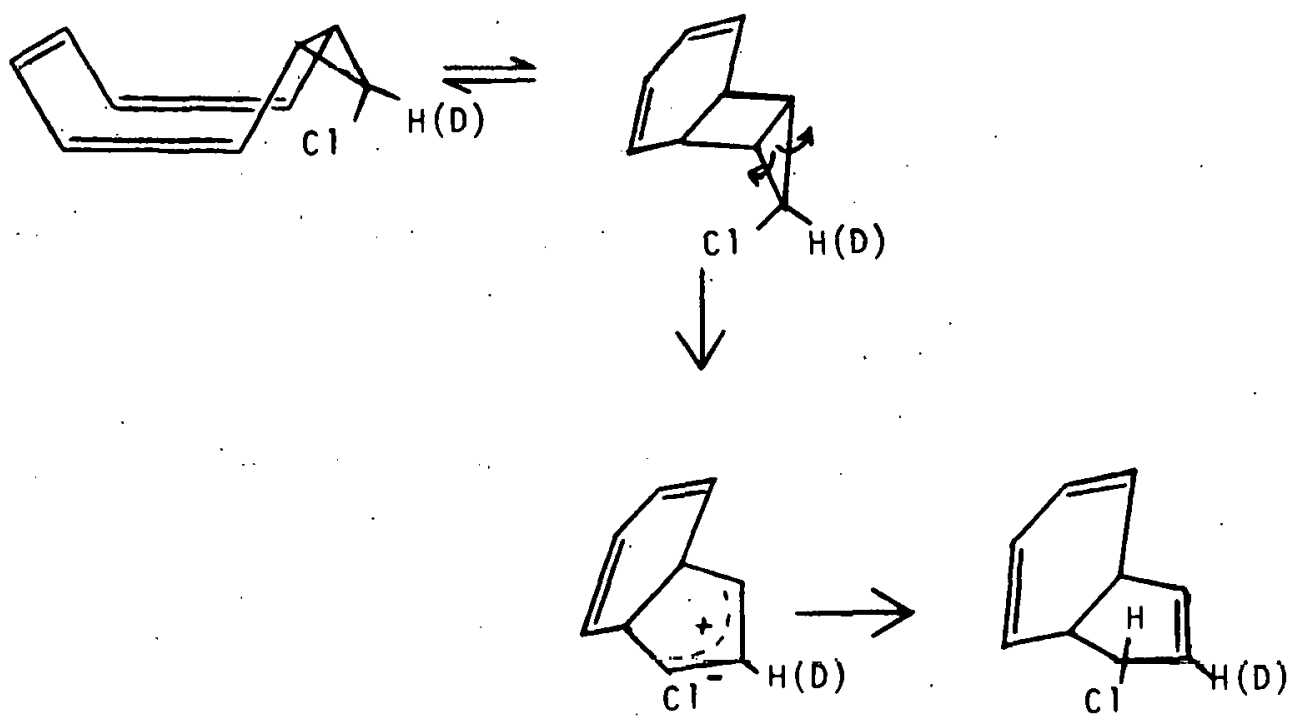

When considering the stereochemistry of the cyclononatetraene intermediate, Staley and Henry $(8,9)$ postulated that symmetry-allowed conrotatory concerted ring opening of bicyolononatrione would lead to cis, cis, cis, trans-cyclononatetraene (13) which would then proceed through dis.rotatory ring closure to trans-8,9-dihydroindene (14) (Equation 7). 
Although they discovered some examples of 9,9-dialkyl derivatives that did yield trans fused rings in the 8,9-dihydroindene system, most rearrangements of bicyclononatrienes were found to lead to cis fused rings. For a cis fused ring, this mechanistic scheme would not obey orbital symmetry rules because conrotatory ring closure, required to form a cis fused ring, does not follow orbital symmetry considerations (6).

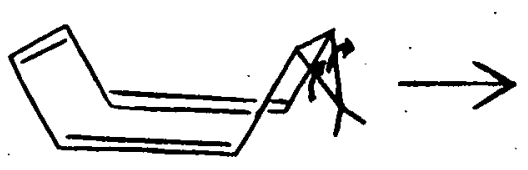

9

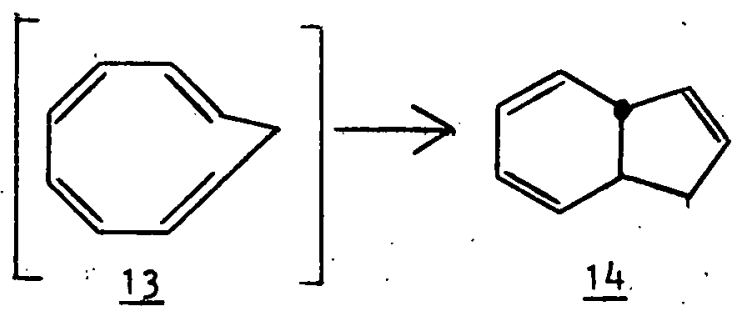

By use of trapping experiments, where the intermediate state would be "trapped" by reaction with a selected stereo-specific reagent, Anastassiou and Griffith (10) were able to hypothesize that the intermediate state for the thermolys is of bicyclononatriene and anti-9-chlorobicyclononatriene was not cis $^{3}$, trans-1,3,5,7-cyclononatetraene but actually cis $^{2}$, trans, cis-1,3,5,7-cyclononatetraene. Their results, as summarized in Scheme I, predicted a "Cope" rearrangement of cis-bicyclo[6.1.0]nona-2,4,6-triene to 15 , which could then undergo symmetry-allowed conrotatory opening to give the desired cis $^{2}$, trans, cis-cyclonona-1,3,5,7tetraene $(16)$. The symmetry-allowed thermal ring closure of the cis ${ }^{2},-$ $\underline{\text { trans, }}$ cis-cyclononatetraene intermediate would then lead directly to trans $-8,9$-dihydroindene (14). Since cis ${ }^{4}$-cyclononatetraene (17) is 
a precursor to cis fused dihydroindene $(11,12)$, a symmetry-forbidden rearrangement of bicyclo[5.2.0]nona-1,4,7-triene to $\mathrm{cis}^{4}$-cyclononatetraene could then lead to the observed formation of cis-8,9-dihydroindene (6). To account for such an obverse conjecture, they postulated that, on the basis of kinetics $\left(k_{-1} \gg k_{2}\right)$; an eventual drain of bicycio[5.2.0]nona-1,4,7-triene (15), to cis $^{4}$-cyclononatetraene (17) would occur (10).

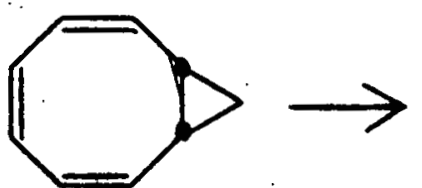

$\underline{4}$

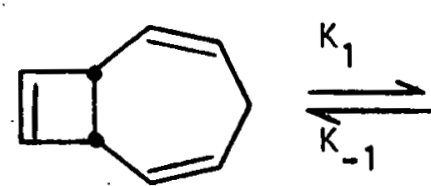

115

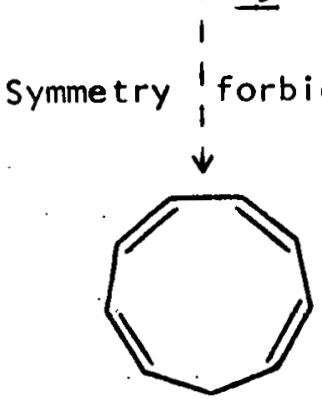

16

17
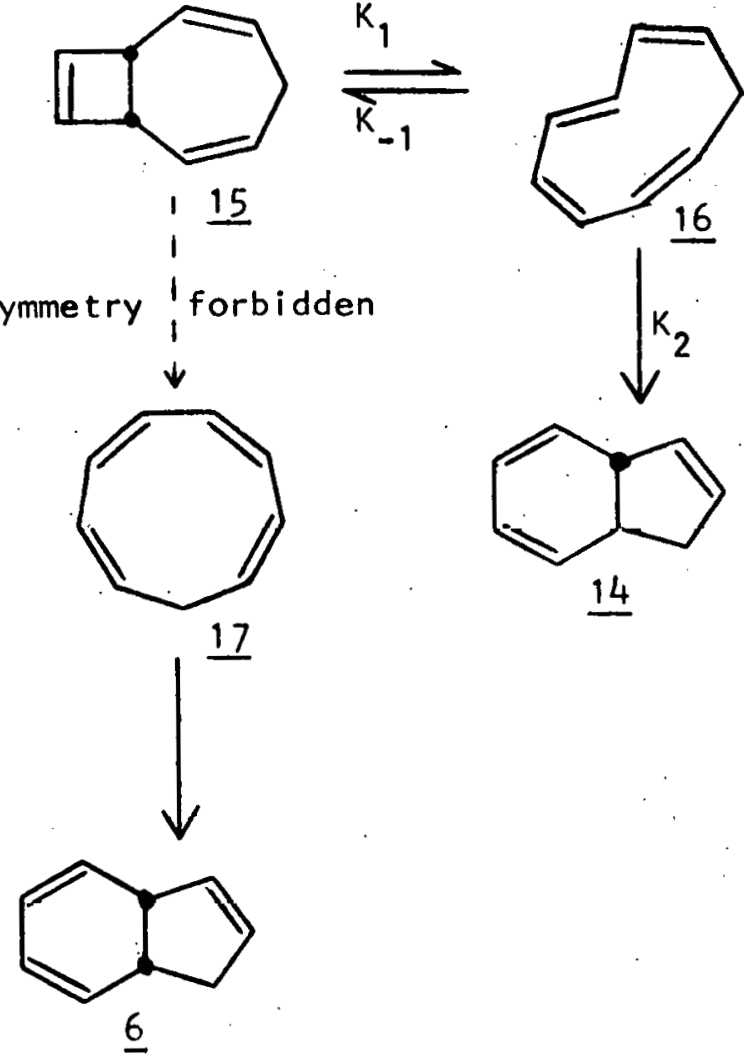
Electrophilic Cycloadditions to cis-Bicyclo[6.1.0]nona-2,4,6-triene Until the late 1960 's only rudimentary investigations had been carried out on the electrophilic cycloaddtion reactions of cis-bicyclo[6.1.0]nona-2,4,6-triene. More recently, such electrophiles as chlorosulfonyl isocyanate (CSI) and tetracyanoethylene (TCNE) have been used. under a variety of conditions to lead to as many of a variety of cycloaddition products. In 1964, Katz and Garratt (3) first noted that the cycloaddition of TCNE to cis-bicyclo[6.1.0]nonatriene and 8,9-dihydroindene led to two different adducts, but they did not suggest any structural possibilities for these adducts. Subsequently, La Lancette and Benson (4) discovered that both 9-chlorobicyclononatriene and 1-chloro8,9-dihydroindene react at room temperature with TCNE to give the same adduct $(\underline{18)}$.

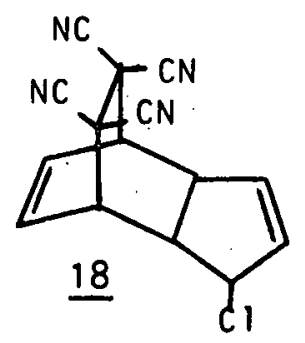

The question then arose as to the actual structural configuration of the TCNE adduct of bicyclononatriene. Okamura and Osborn (13) narrowed the structural possibilities to one that corresponds formally to an adduct produced by the cycloaddition of TCNE with cyclononatetraene. They suggested compound 1 by structural assignment from nmr and uv spectra of the compound and postulated that $\mathrm{cis}^{2}$, trans, cis-cyclonona$1,3,5,7$-tetraene (16) was the intermediate involved. 


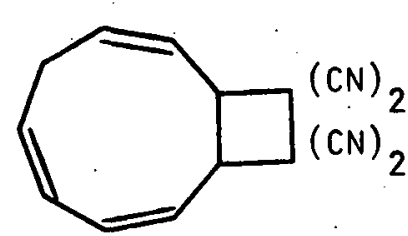

1

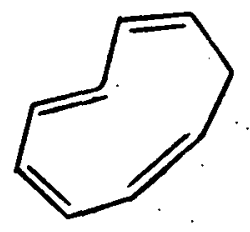

16

Baxter and Garratt (14) published a paper simultaneously with Okamura and Osborn's. They supported Okamura and Osborn's structure (1) for the cycloaddition of TCNE with bicyclononatriene and recognized the exact stereochemistry of the ring juncture had to be known before attempting to supply a mechanism for the reaction. The nmr spectrum was of no help in elucidating the stereoconfiguration of the molecule. The compound appeared to be thermally stable, but endeavors to catalytically hydrogenate it led to a slow uptake of more than a theoretical amount of hydrogen. Since the TCNE adduct of bicyclononatriene did not involve the tricyclic valence tautomer 19 , and the reaction led almost completely to only one formal cyclononatetraene product, Baxter and Garratt (14) suggested that the reaction was nonconcerted.

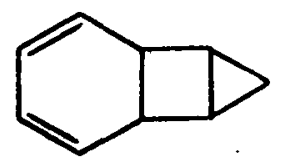

19

L. A. Paquette et al. $(15,16)$, after detailed study, have proposed a nonconcerted mechanistic scheme for the electrophilic addition to bicyclo[6.1.0]nonatriene. While studying the two conformations of cis-bicyclo[6.1.0]nona-2,4,6-triene (endo (20a) and exo (20b) fusion 
of the cyclopropane ring with respect to the cyclooctatriene ring), they proposed that only one possible conformation (20b) could lead to electrophilic addition (15). They rationalized that initial bonding of the
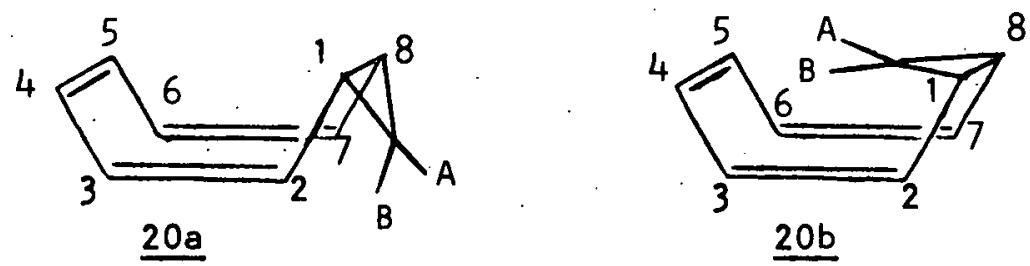

dienophile to a $\mathrm{sp}^{2}$-hybridized carbon atom would be prevalent, but stabilization, from delocalization of the cationic charge in the triene segment could not occur in either $20 \mathrm{a}$ or $\underline{20 \mathrm{~b}}$ due to the orthogonality. of the double bonds.

Paquette et al. (15) proposed that initial bonding of the electrophile would not occur at carbon atoms $C_{2}$ or $C_{4}$ since the vacated $p$ orbitals on carbon atoms $C_{3}$ and $C_{5}$, respectively, would be spacially oriented inappropriately for stabilization (21a, 21b). The vacant orbitals are directed away from neighboring $\mathrm{sp}^{2}$-hybridized carbon atoms and also away from the orbitals on the cyclopropane ring.

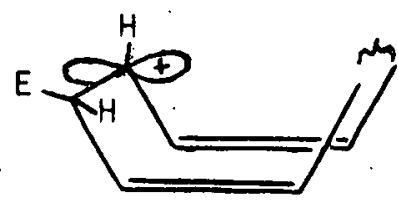

$\underline{21 a}$

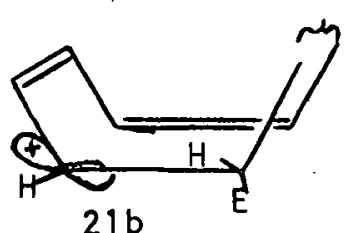

$21 \mathrm{~b}$

In the case of $20 \mathrm{~b}$, initial bonding of the electrophile to $\mathrm{C}_{3}$ would lead to stabilization of the carbonium ion (22), since the vacant p. orbital of $C_{2}$ would align with the internal cyclopropyl bond such that 
delocalization of the cationic center could occur $(17,18)$. When looking at electrophilic attack at $C_{3}$ in $20 \mathrm{a}$, one will observe that the vacant p orbital on $\mathrm{C}_{2}$ is essentially destabilized due to its positioning toward the center of the cyclopropane ring $(23)(17,18)$. Therefore, the first step towards the reaction of an electrophile with bicyclononatriene would be bonding at $C_{3}$ on the endo fused bicyclononatriene system (20b).

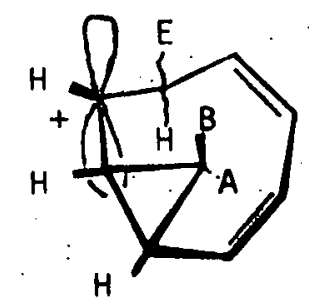

22

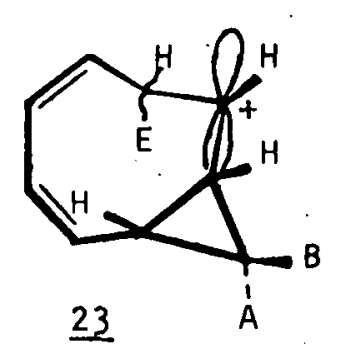

23

Paquette et al. (15) theorized that the reactivity of the 9-substituted derivatives of the bicyclononatriene system depended upon their capability to attain the endo fused conformation. As exhibited in

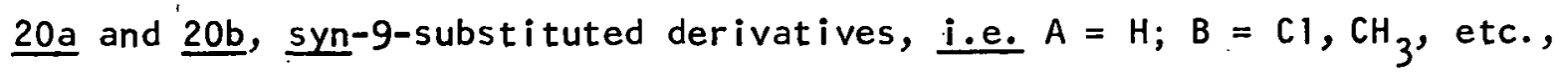
of bicyclononatriene would probably attain the exo conformation (20a) due to steric hindrance of the substituted groups with the double bond most remote from the cyclopropane ring, while anti-9-substituted derivatives, i.e. $B=\mathrm{H} ; \mathrm{A}=\mathrm{Cl}, \mathrm{CH}_{3}$, etc., could attain the endo positioning (20b) needed for reaction. Paquette et al. proved this to be the case by demonstrating the lack of reactivity of the syn-9-substituted derivatives of bicyclononatriene towards electrophilic addition. 
Warner and Winstein (19) reacted bicyclononatriene with the simplest of electrophiles - the proton. From analysis using NMR techniques, they deduced that a 1,3-bishomotropylium ion (24) had been produced. As reinforcement to the Paquette et al. thesis (15), they proposed an initial attack of the proton to carbon atom $\mathrm{C}_{3}$.

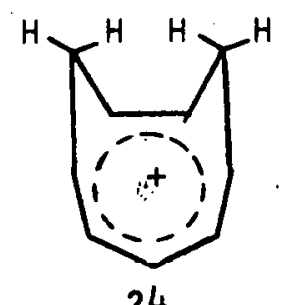

24

The 1,3-bishomotropylium ion is composed of a system of five $s p^{2}-$ hybridized carbon atoms separated from two $\mathrm{sp}^{2}$-hybridized carbon atoms by two methylene bridges. Theoretically, conjugation occurs between all $7 . \mathrm{s}^{2}$-hybridized carbons to glve an aromatic system (H'uckel's $4 n+2$ rule) by conjugating across the methylene bridges. Warner and Winstein (19) believed this conjugation did occur across the methylene bridges on account of similar control experiments they ran on cyclooctatetraene (25) (Equation 8). They found the $\mathrm{nmr}$ data for $\underline{21}$ and $\underline{23}$ to be significantly different as to justify the seven carbon aromaticity of the 1,3-bishomotropylium ion.

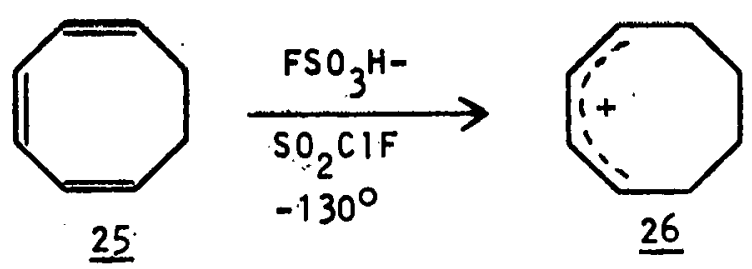


Warner and Winstein also postulated that the methylene bridges were cis disposed (24) as opposed to trans disposed (27) basing their analys is on chemical shift differences of inner and outer protons in the nmr. spectra and the charge distribution observed for the ion.

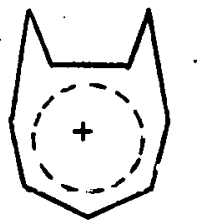

$\underline{24}$

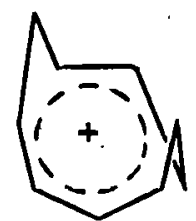

$\underline{27}$

Paquette et al. (15) believed, that after electrophilic attack at carbon atom $\mathrm{C}_{3}$ in the tub conformation of bicyclononatriene, the inner cyclopropyl bond would break and the molecule would rearrange to form a 1,3-bishomotropylium ion. The question arose as to what the stereochemistry of the bishomotropylium ion was and how the dienophile attacked the molecule. Scheme II (15) shows the four possible combinations (28-31) of cis or trans methylene bridges with endo or exo bonding of the dienophile.

Paquette et al. (15) used chlorosulfonyl isocyanate (CSI) as an electrophilic reagent to support their hypothesis. The reaction of CSI with bicyclononatriene (4) and 9-methylbicyclononatriene (37) led to trans fused $\beta-1$ actams $(\underline{36}, \underline{38})$ in both cases (Equations 9 and 10 ) as suggested by nmr data and catalytic hydrogenation to stereochemically elucidated compounds (15). These observations cut the number of possible modes of reaction from four to two. 


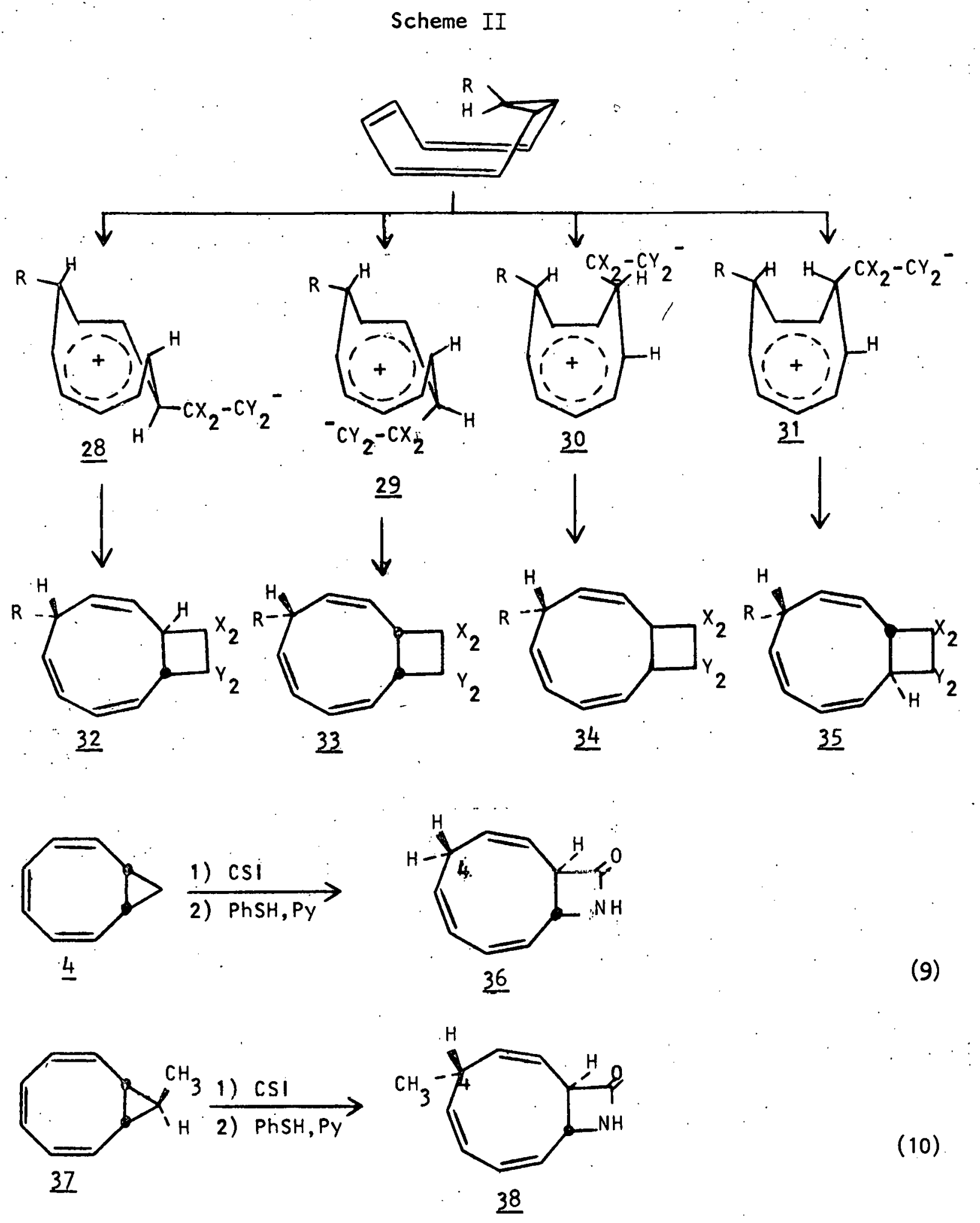


If the stereochemistry of carbon atom $C_{4}$ was known in $\underline{38}$, one could identify the reaction mode and the stereochemistry of the intermediate 1,3-bishomotropylium ion. Consequently, the $x$-ray analysis of 38 was performed. The stereochemistry of the molecule placed the hydrogen atoms of carbon atoms $c_{4}$ and $c_{1}$ trans to each other; therefore, 28 was assumed to be the mechanistic intermediate (15). This result directly contradicts Warner and Winsteln's (19) prediction that the 1,3-bishomotropylium ion has cls positloned methylene brldges.

To further Investigate their mechanistic sscheme, Paquette selected the TCNE adduct of cis-bicyclononatriene (1). By resolving the stereochemistry of 1 , the reaction mechanism would again be limited to two possibilities in Scheme II. But the stereochemistry of 1 was apparently unresolvable by ordinary chemical techniques such as NMR and hydrogenation to a stereochemically elucidated compound (14). Therefore, X-ray crystal structure analysis was the obvious alternatlve method for determining the stereochemistry of 1 .

In this thesis, conclusive stereochemical results for the structure of the TCNE adduct of cls-blcyclo[6.1.0]nona-2,4,6-triene are shown, thereby narrowlng the four mechanistic pathways in Scheme II to two. After the resolution of the stereochemistry of 1 had been accomplished, Paquette and co-workers found that the cycloaddition of TCNE to 9-chlorobicyclo[6.1.0]nona-2,4,6-triene (2), not only produced compound 18 in $50 \%$ yield, but careful extraction from the mother liquor also yielded compound $\underline{2}$ (Equation 11). 


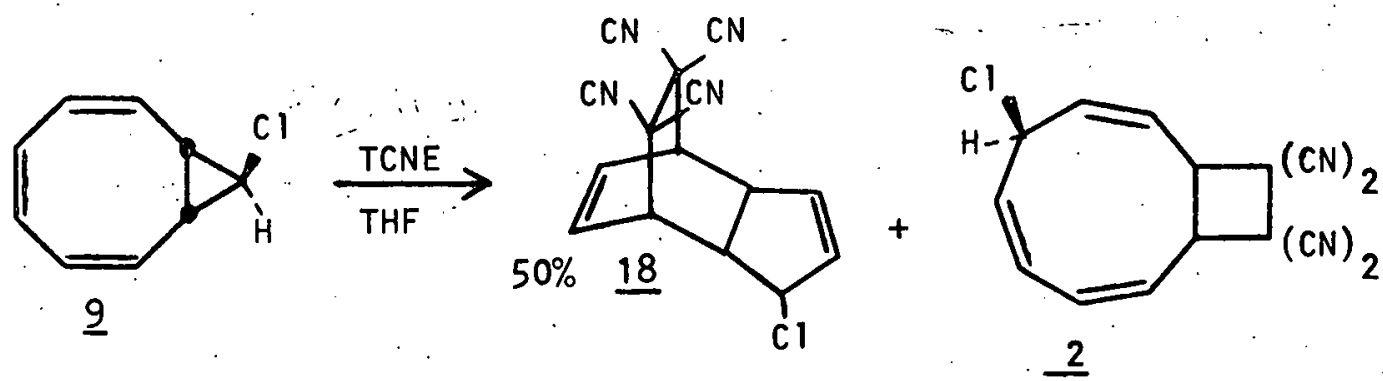

The $X$-ray analysis of $\underline{2}$ is also reported in this thesis. On the basis of this analysis, the mechanistic pathway in Scheme II was again narrowed to one as it had been for the CSI adduct of 9-methylbicyclononatriene. 
THE CRYSTAL STRUCTURE OF $10,10,11,11$-TETRACYANOB ICYCLO $[7 \cdot 2.0]$ UNDECA-2, 4,7-TRIENE.

Preliminary Investigation and Data Collection

Clear acicular crystals of $10,10,11,11$-tetracyanobicylo[7.2.0]undeca-2,4,7-trlene (1), (kindly supplied by L. A. Paquette) were obtained by slow evaporation of methylene chloride solution. Preliminary X-ray photographs revealed Laue symmetry of $\mathrm{mmm}$, which places the crystals in the orthorhombic space group class. Systematlc extinctions were observed for $\operatorname{Okl}(k=2 n+1), \operatorname{hol}(\ell=2 n+1)$, and $h k O(h+k=2 n+1)$ and uniquely determined the space group to be $P_{b c n}\left(D_{2 h}^{14}\right)$. A congruent calculated and experimental density $\left(p=1.23 \mathrm{~g} / \mathrm{cm}^{3}\right)$ disclosed $z=8$ (or one molecule per asymmetric unit). A crystal with approximate dimensions of $0.15 \times 0.10 \times$ $0.10 \mathrm{~mm}$ was mounted along its $b$ axis and transferred to a fully-automated Hilger-Watts four-circle diffractometer equipped with a scintillation detector system. From accurately measured $\theta$ values, cell constants were calculated to be $a=15.4(1) \&, b=6.93(1) \&, c=24.97(1) \AA$.

Data were collected at room temperature for the hkl octant within a $2 \theta$ sphere of $50^{\circ}$ using $\mathrm{Zr}$-filtered MoK $\alpha$ radiation $(0.7107 \AA)$. An $\omega-2 \theta$ scan technique was employed with backgrounds measured at $\theta_{\text {hkl }} \pm\left(0.25+0.01 \times \theta_{\text {hkl }}\right)$.

Throughout data collection, periodic measurements were made on three assigned standard reflections to assess crystal and electronic stability. The intensities were corrected for Lorentz and polarization factors and the estimated deviation of the Intensity; $\sigma(I)$, was based on [(total count) + (background count) +0.05 (total count) ${ }^{2}+0.05$ (background count $\left.)^{2}\right]^{\frac{1}{2}}$. 
The estimated deviation of $F, \sigma(F)$, was calculated from

$$
\sigma(F)=\{[I+\sigma(I)] / L p\}^{\frac{1}{2}}-(I / L p)^{\frac{1}{2}}(20)
$$

A total of 2220 reflections were judged observed using the criterion that $F>3 \sigma(F)$ for any data to be observed. Corrections were not made for anomolous dispersion, absorption $\left(\mu=0.835 \mathrm{~cm}^{-1}\right)$, or decomposition.

\section{Solution and Refinement}

Normalized structure factors were calculated from a Wilson Plot in a standard way (21). Phases were assigned to the 436 E's greater than 1.5 by the iterative application of Sayre's equation (22). An E-map was computed from the most consistent set of phased E's, and all 20 nonhydrogen atom positions were located (23). Full-matrix least-squares refinements on

$$
\underset{\text { obs }=1}{N} \omega|| \text { Fobs }|-| \text { Fcalc| }\left.\right|^{2},
$$

where $\omega=[1 / \sigma(F)]^{2}$, with anisotropic temperature factors reduced the conventional welghted and unwelghted discrepancy indexes to $R=13.6 \%$ and $R=11.0 \%$, respectively. At this polnt, hydrogen atom positions were calculated for the trigonal and tetrahedral carbon atoms with $\mathrm{C}-\mathrm{H}$ bond distances set at $1.08 \AA$. Introducing the hydrogen atoms and refining on the parameters of the nonhydrogen atoms (321 parameters) lowered the weighted discrepancy index to $R=9.4 \%$ and the unweighted to $R=8.5 \%$ for the observed data. The scattering factor tables were those of Hanson et al. (24). In Tables 1 and 2 are listed the final $X$-ray coordinates and thermal parameters, respectively, along with thelr standard 
deviations (25). Figure 1 lists the observed and calculated structure factors for 1 (25) based on the parameters shown in Tables 1 and 2.

\section{Description and Discussion of Structure}

The geometrical configuration of 1 is illustrated in Figure 2 (26). As can be clearly seen, the fusion of the cyclobutane and cyclononane rings is trans with a $C(2)-C(1)-c(9)-c(8)$ dihedral angle of $100^{\circ}$. PuckerIng of the cyclobutane ring and skeletal strain in the ring are evident from the $c(1)-c(11)-c(10)-c(9)$ dihedral angle and the bond lengths (1.57 $1.59 \AA)$, which are longer than expected for such a system (27). The $c(1)-c(2)-c(3)-c(4)$ system varles from coplanarity by $8^{\circ}$ which imp iies that torslonal strain does exist on the $c(2)-c(3)$ double bond. The dihedral angle of the butadiene portion, $c(2)-c(5)$, is $57^{\circ}$. Figure 3 (26) illustrates the positions of the symmetry-related molecules in the unit cell. All bond lengths and bond angles agree with accepted values and are listed, with their standard deviations, in Tables 3 and 4 (28). Table 5 lists selected dihedral angles for 1 . 
Table 1. Final fractional coordinates ${ }^{a}$ for 1

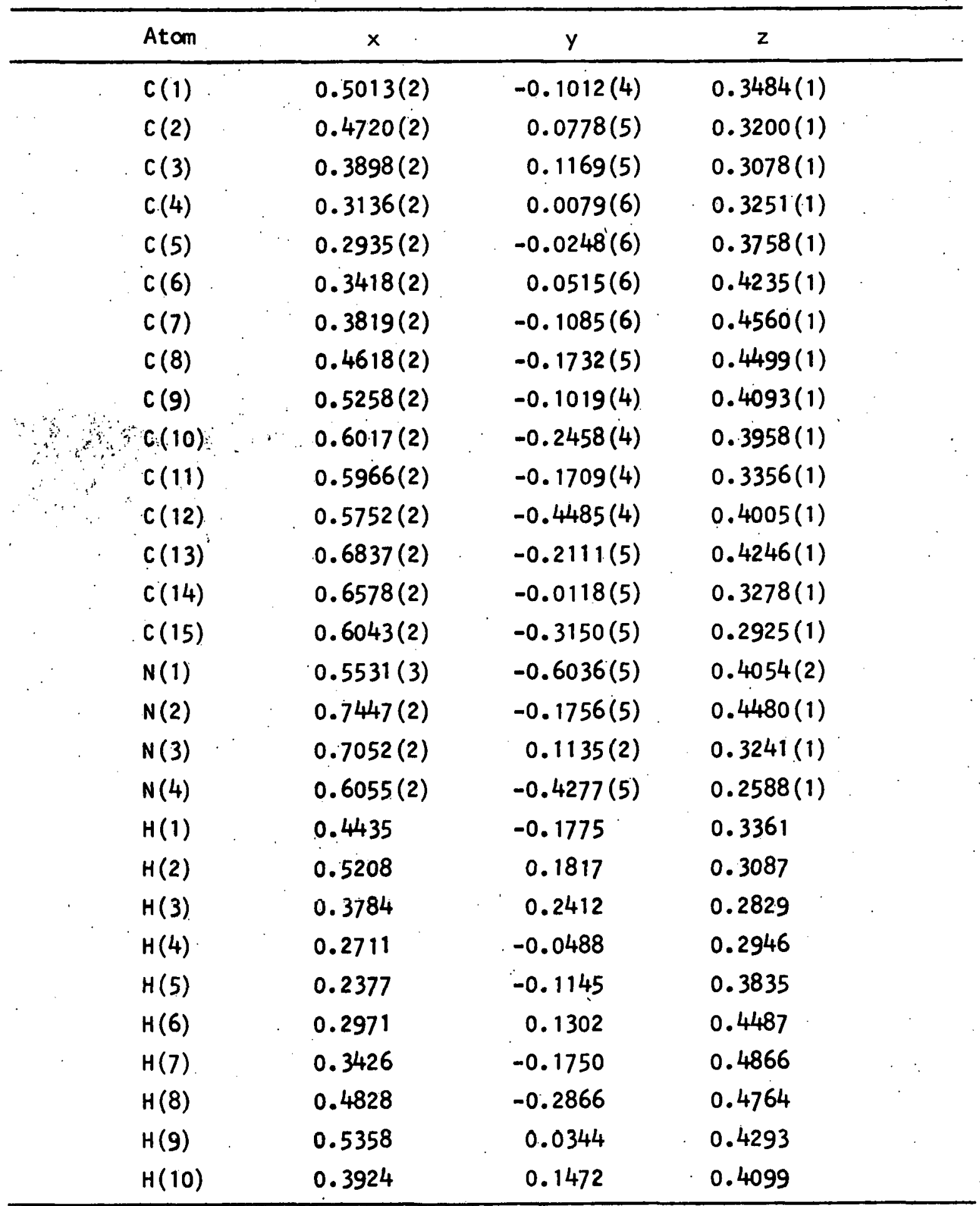

${ }^{a}$ The estimated standard deviation is given in parentheses for the least significant figure: 
Table 2. Final values of the thermal parameters $\left(\times 10^{4}\right)$ and their standard deviations for 1 . The form of the temperature factor is exp $\left(-\beta_{11} h^{2}-\beta_{22} k^{2}-\beta_{33} \ell^{2}-2 \beta_{13} h l-2 \beta_{23} k l\right)^{a}$

\begin{tabular}{llllrrr}
\hline Atom & $\beta_{11}$ & $\beta_{22}$ & $\beta_{33}$ & $\beta_{12}$ & $\beta_{13}$ & $\beta_{23}$ \\
\hline$C(1)$ & $37(1)$ & $214(7)$ & $11(1)$ & $0(3)$ & $1(1)$ & $4(1)$ \\
$C(2)$ & $45(2)$ & $218(8)$ & $11(1)$ & $1(3)$ & $3(1)$ & $6(2)$ \\
$C(3)$ & $50(2)$ & $267(9)$ & $12(1)$ & $17(3)$ & $1(1)$ & $1(2)$ \\
$C(4)$ & $46(2)$ & $334(10)$ & $18(1)$ & $12(4)$ & $-2(1)$ & $-2(2)$ \\
$C(5)$ & $46(2)$ & $353(11)$ & $21(1)$ & $-4(4)$ & $3(1)$ & $5(2)$ \\
$C(6)$ & $56(2)$ & $315(10)$ & $15(1)$ & $21(4)$ & $6(1)$ & $1(2)$ \\
$C(7)$ & $57(2)$ & $332(10)$ & $14(1)$ & $-16(4)$ & $8(1)$ & $6(2)$ \\
$C(8)$ & $59(2)$ & $247(9)$ & $12(1)$ & $-11(4)$ & $5(1)$ & $9(2)$ \\
$C(9)$ & $45(1)$ & $196(7)$ & $11(1)$ & $2(3)$ & $0(1)$ & $3(2)$ \\
$C(10)$ & $42(1)$ & $182(6)$ & $13(1)$ & $-3(3)$ & $-2(1)$ & $1(1)$ \\
$C(11)$ & $37(1)$ & $218(7)$ & $11(1)$ & $0(3)$ & $-1(1)$ & $-7(1)$ \\
$C(12)$ & $55(2)$ & $194(8)$ & $18(1)$ & $5(3)$ & $-7(1)$ & $3(2)$ \\
$C(13)$ & $49(2)$ & $214(8)$ & $13(1)$ & $1(3)$ & $-2(1)$ & $7(2)$ \\
$C(14)$ & $38(1)$ & $259(8)$ & $259(1)$ & $12(3)$ & $2(1)$ & $-3(2)$ \\
$C(15)$ & $37(1)$ & $274(9)$ & $18(1)$ & $8(3)$ & $-4(1)$ & $-19(2)$ \\
$N(1)$ & $89(2)$ & $215(7)$ & $30(1)$ & $-13(3)$ & $-8(1)$ & $5(2)$ \\
$N(2)$ & $54(2)$ & $358(10)$ & $18(1)$ & $-4(3)$ & $-8(1)$ & $6(2)$ \\
$N(3)$ & $56(2)$ & $330(9)$ & $19(1)$ & $-22(3)$ & $4(1)$ & $0(2)$ \\
$N(4)$ & $64(2)$ & $407(10)$ & $25(1)$ & $18(4)$ & $-4(1)$ & $-54(2)$ \\
\hline
\end{tabular}

${ }^{a}$ The hydrogen atoms were given an isotropic temperature factor of $6 \AA^{2}$ which was not varied, 
Figure 1. Comparisons of the observed and calculated structure factors (in electrons $\times 10$ ) for 1 


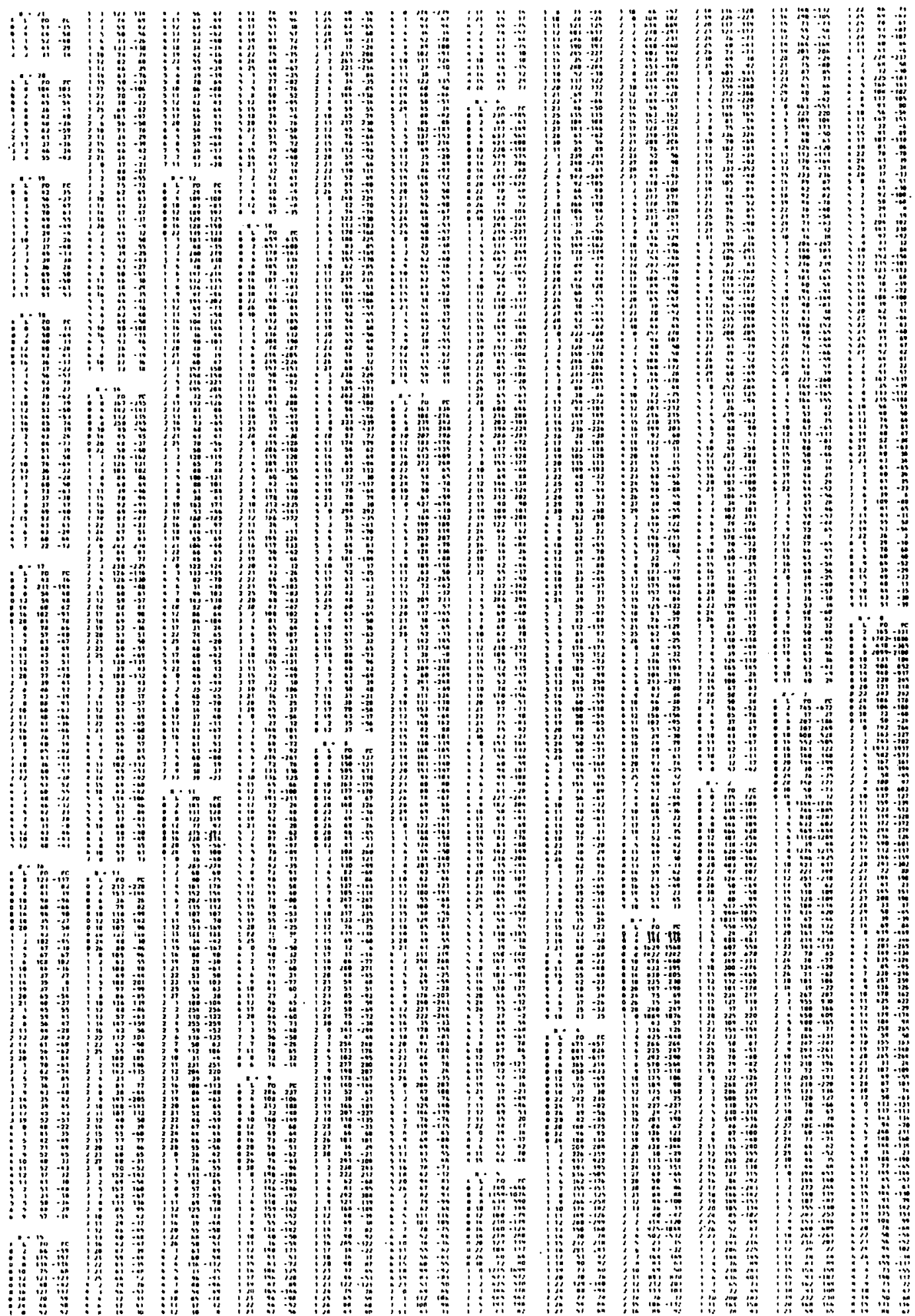


Figure 2. A computer generated perspective drawing of $\underline{1}$ 


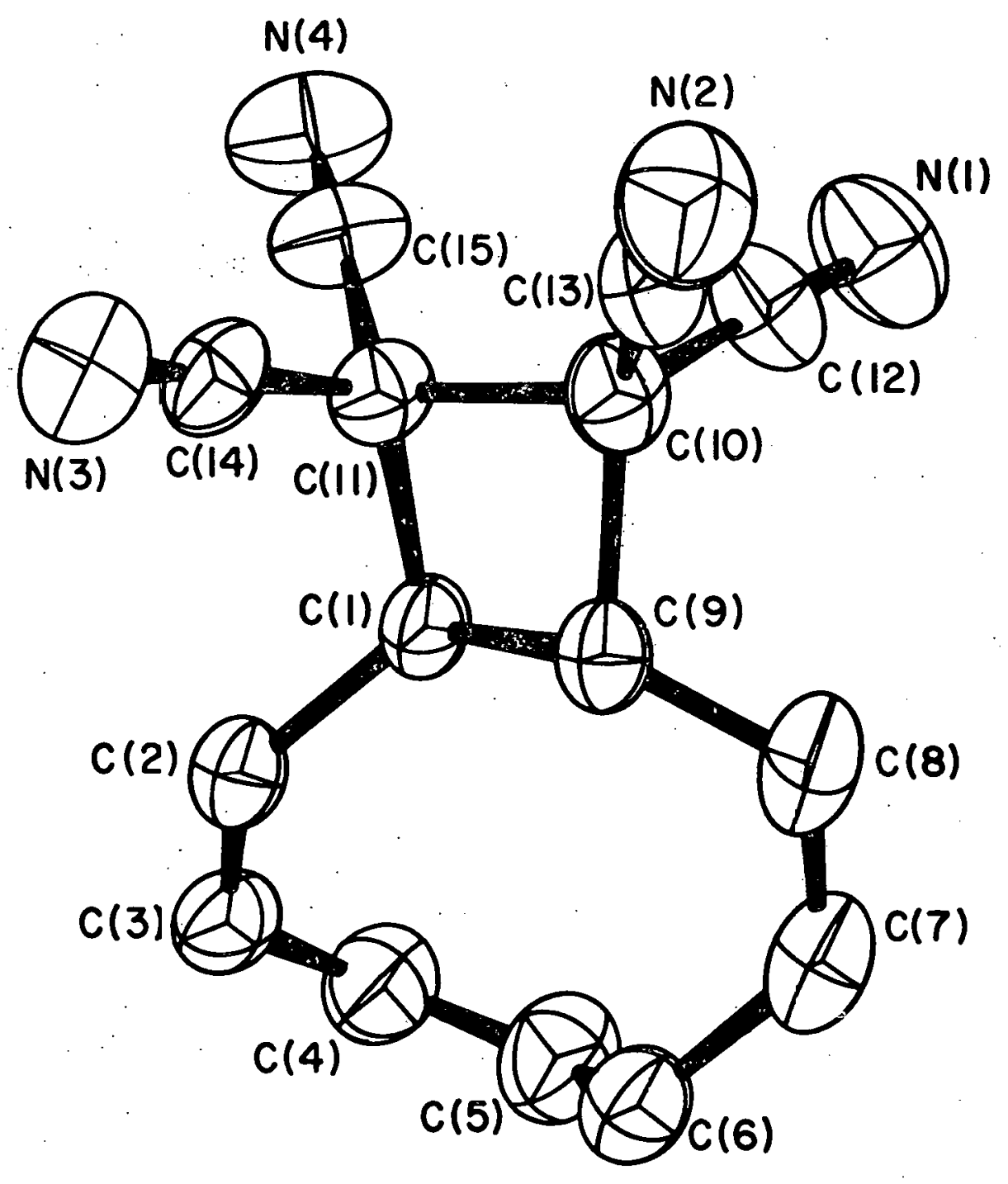


Figure 3. A computer gene-ated perspective drawing of the unit cell of 1 . $A$ is the reference molecule at $(x, y, z)$. The other molecules are generated in the following way: $B\left(\frac{1}{2}-x, \frac{1}{2}-y, \frac{1}{2}+z\right)$; $C\left(\frac{1}{2}+x, \frac{1}{2}-y,:=z\right) ; \quad D\left(1-x, y, \frac{1}{2}-z\right) ; E(1-x, 1-y, 1-z)$; $F\left(\frac{1}{2}+x, \frac{1}{2}+y, \frac{\bar{i}}{2}-z\right) ; G\left(\frac{1}{2}-x, \frac{\frac{z}{2}}{2}+y, z\right) ; H\left(x,-y, \frac{1}{2}+z\right)$ 


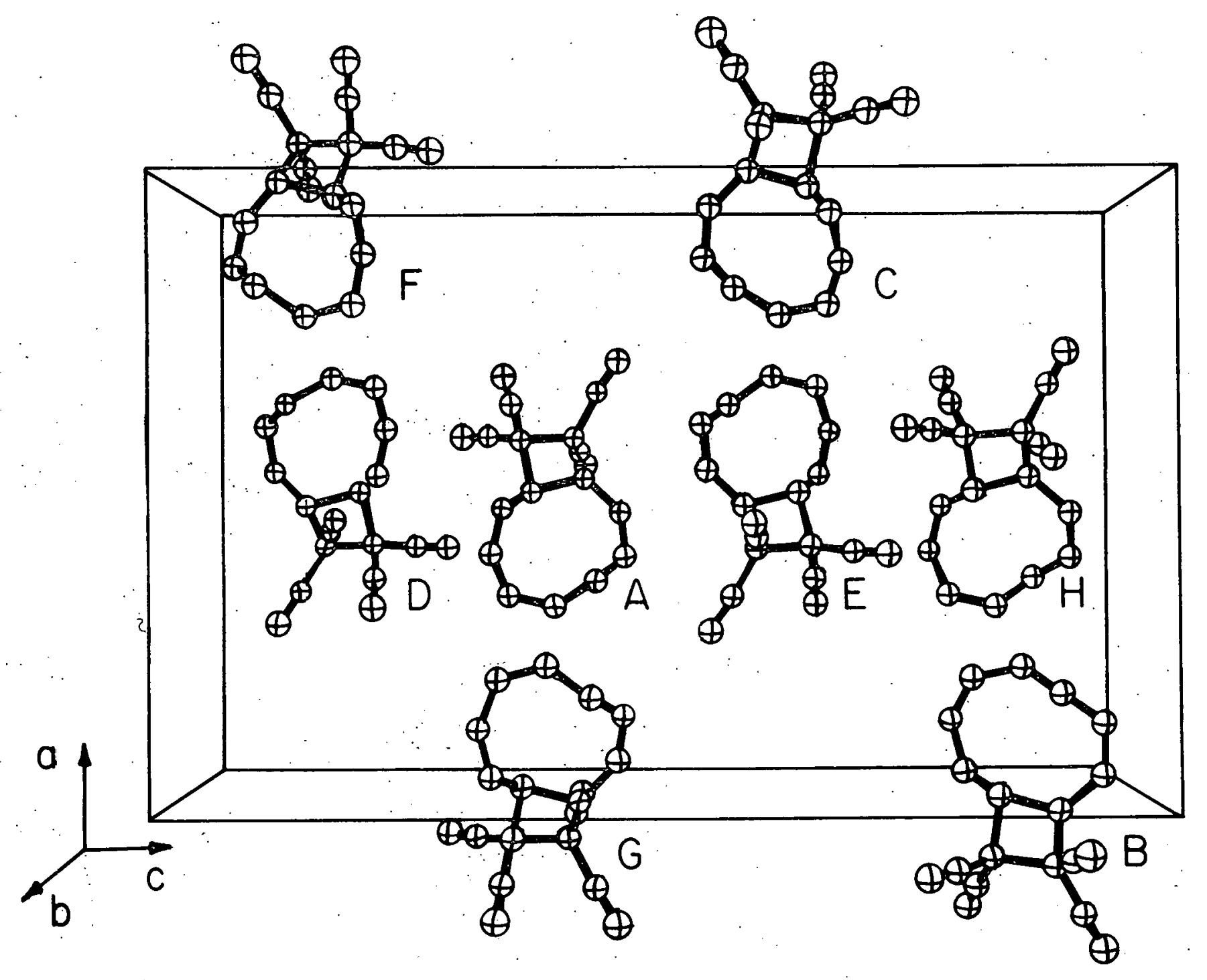


Table 3. Selected bond lengths ${ }^{a, b}$ for 1

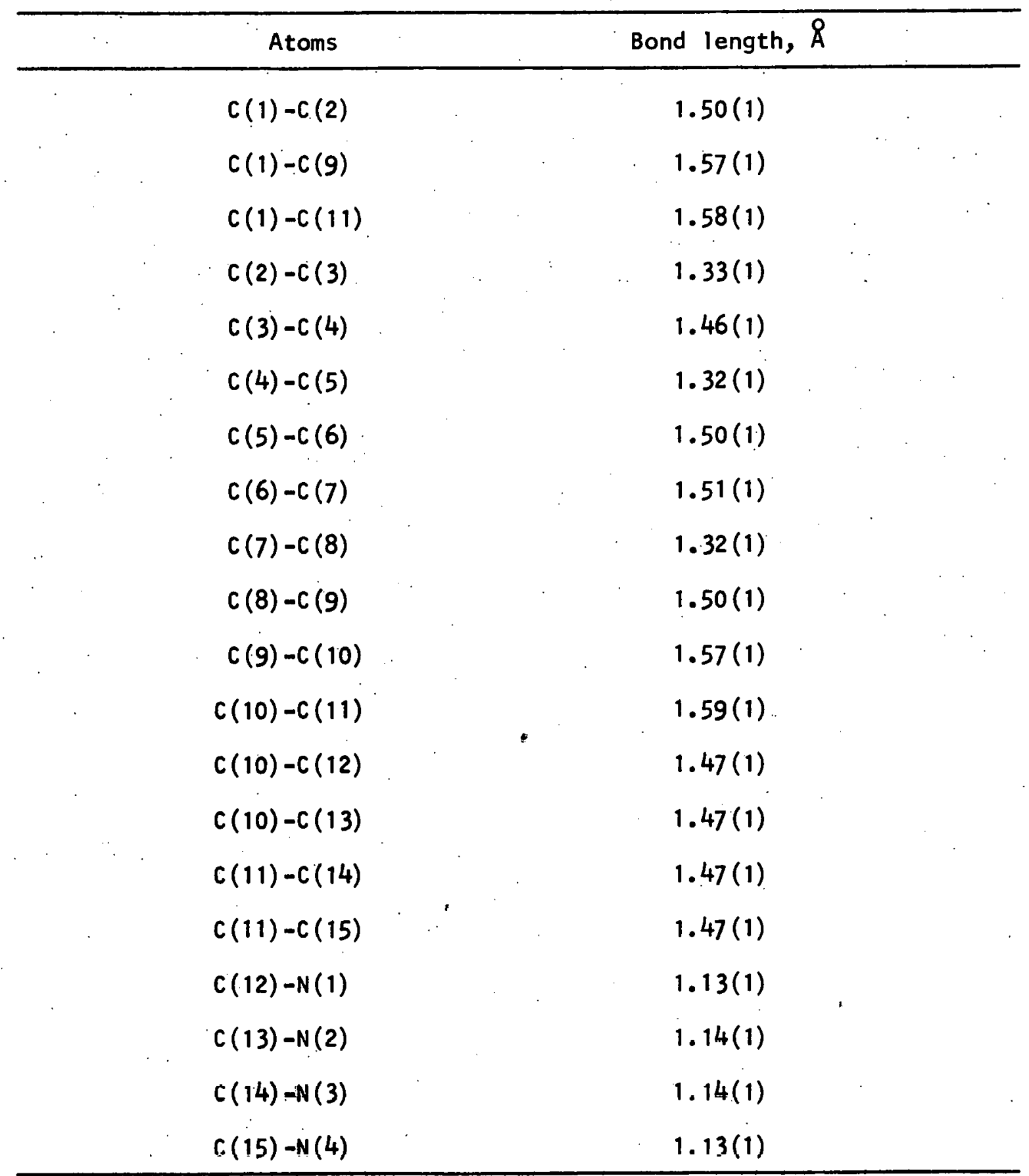

${ }^{a}$ All carbon-hydrogen bond lengths were set at $1.08 \AA$.

bThe estimated standard deviation is glyen in parentheses for the least stonificant figure. 
Table 4. Selected interatomic angles ${ }^{a}$ for 1

\begin{tabular}{|c|c|c|c|}
\hline Atoms & Angle, degrees & Atoms & Angle, degrees \\
\hline$c(2)-c(1)-c(9)$ & $122(1)$ & $c(9)-c(10)-c(12)$ & $113(1)$ \\
\hline$c(2)-c(1)-c(11)$ & $116(1)$ & $c(9)-c(10)-c(13)$ & $115(1)$ \\
\hline$c(9)-c(1)-c(11)$ & $88(1)$ & $C(11)-c(10)-c(13)$ & $117(1)$ \\
\hline$c(1)-c(2)-c(3)$ & $124(1)$ & $c(12)-c(10)-c(13)$ & $111(1)$ \\
\hline$c(2)-c(3)-c(4)$ & $126(1)$ & $C(1)-C(11)-C(10)$ & $88(1)$ \\
\hline$c(3)-c(4)-c(5)$ & $124(1)$ & $c(1)-c(11)-c(14)$ & $113(1)$ \\
\hline$c(4)-c(5)-c(6)$ & $126(1)$ & $c(1)-c(11)-c(15)$ & $115(1)$ \\
\hline$c(5)-c(6)-c(7)$ & $112(1)$ & $C(10)-c(11)-c(14)$ & $110(1)$ \\
\hline$c(6)-c(7)-c(8)$ & $125(1)$ & $C(10)-C(11)-C(15)$ & $118(1)$ \\
\hline$c(7)-c(8)-c(9)$ & $126(1)$ & $C(14)-c(11)-c(15)$ & $111(1)$ \\
\hline$c(8)-c(9)-c(1)$ & $120(1)$ & $N(1)-C(12)-C(10)$ & $178(1)$ \\
\hline$c(8)-c(9)-c(10)$ & $115(1)$ & $N(2)-C(13)-C(10)$ & $176(1)$ \\
\hline$c(10)-c(9)-c(1)$ & $89(1)$ & $N(3)-C(14)-C(11)$ & $177(1)$ \\
\hline$C(9)-C(10)-C(11)$ & $88(1)$ & $N(4)-C(15)-C(11)$ & $176(1)$ \\
\hline
\end{tabular}

a The standard deviation (in parentheses) is calculated from the inverse matrix of least squares refinement. 
Table 5. Selected dihedral angles for 1

\begin{tabular}{cc}
\hline Atoms & Angle, degrees \\
\hline$c(1)-c(2)-c(3)-c(4)$ & 57 \\
$c(2)-c(3)-c(4)-c(5)$ & 4 \\
$c(3)-c(4)-c(5)-c(6)$ & 2 \\
$c(6)-c(7)-c(8)-c(9)$ & 100 \\
$c(8)-c(9)-c(1)-c(2)$ & 22 \\
$c(1)-c(9)-c(10)-c(11)$ & 21 \\
$c(1)-c(11)-c(10)-c(9)$ & 22 \\
$c(10)-c(9)-c(1)-c(11)$ & 21 \\
$c(10)-c(11)-c(1)-c(9)$ & 2 \\
\hline
\end{tabular}


THE CRYSTAL STRUCTURE OF 6-CHLORO$10,10,11,11$-TETRACYANOB I CYCLO $[7,2.0]$ UNDECA-2, 4,7-TRIENE

Preliminary Investigation and Data Collection

Crystals of 6-chloro-10,10,11,11-tetracyanobicyclo[7.2.0]undeca2,4,7-triene (2) ( $k$ Indly supplied by L. A. Paquette) were grown by slow evaporation of methylene chloride solution. Microscopic examination revealed clear, needle-like crystals with well-defined faces. A crystal with approximate dimensions of $0.15 \times 0.10 \times 0.10 \mathrm{~mm}$ was selected for diffraction work. Laue symmetry of $\overline{1}$ and the absence of any systematic extinctions defined the space group as elther $P_{1}\left(C_{1}^{1}\right)$ or $P_{1}\left(c_{1}^{1}\right)$. A calculated and obșerved density of $1.36 \mathrm{~g} / \mathrm{cm}^{3}$ for $Z=2$ indicated one molecule per asymmetric unit for the presumed space group $P-1$

A crystal mounted on the $c$ axis was transferred to a fully-automated Hilger-Watts four-circle diffractometer with a scintillation detector system. Cell constants of $a=7.37(2) \AA, b=6.97(3) \AA, c=14.07(2) \AA$, $\alpha=88.6(1)^{\circ}, \beta=76.3(1)^{\circ}$, and $Y=101.7(1)^{\circ}$ were obtained from a leastsquares fit. of accurately measured theta values. All data within a $2 \theta$ sphere of $50^{\circ}$ for the hkl, $\bar{h} k l, h \bar{k} l$, and $\bar{h} \overline{k l}$ octants were collected using Zr-filtered MoK $\alpha$ radlation $(0.7107 \AA)$. A moving crystal-moving counter scan technique was used with backgrounds measured at $\theta_{\text {hkl }} \pm(0.25+$ $\left.0.01 \theta_{h k l}\right)$. Periodlc measurements of three assigned standard reflections were checked to appraise crystal and electronic stability. A decline of $\sim 10 \%$ was noticed in the Intensities of the standard reflections. No correction for this effect was made. The intensities were corrected for 
Lorentz and polarization factors, and $\sigma(I)$ was estimated from [(total count) + (background count) +0.05 (total count) ${ }^{2}+0.05$ (background count $\left.)^{2}\right]^{\frac{1}{2}}$. The estimated deviation of $F, \sigma(F)$, was calculated from $\sigma(F)=\left\{[I+\sigma(I)] / L_{p}\right\}^{\frac{1}{2}}-\left(I / L_{p}\right)^{\frac{1}{2}}(20)$. of the 2332 reflections measured, 1736 were judged observed $(F>3 \sigma(F))$. A small calculated linear absorption coefficient of $2.1 \mathrm{~cm}^{-1}$, indicated that no absorption correction was necessary.

\section{Solution and Refinement}

Normalized structure factors were calculated in a standard way from a Wilson plot (21), and from the statistical distribution of the E's the space group was postulated to be $P_{\overline{1}}$. Phases were assigned to the 230 E's greater than 1.5 by the iterative application of Sayre's equation (22). The most consistent set of phased E's were used to compute an E-map which revealed eighteen of the twenty nonhydrogen atom positions (23). A subsequent electron density map was calculated with phases of the eighteen atom fragment, and the two remaining nonhydrogen atom positions were disclosed (23). Full-matrix least-squares refinements (222 parameters) on $\Sigma \omega||$ Fobs $|-| F c a l c||^{2}$, where $\omega=[1 / \sigma(F)]^{2}$, with anisotropic temperature parameters reduced the conventional weighted and unweighted discrepancy indexes, respectively, to a minimum of $\omega R=10.6 \%$ and $R=8.9 \%$ for the observed reflections. The scattering factors used were those of Hanson et al. (24). Tables 6 and 7 list the final $X-r a y$ coordinates and thermal parameters, respectively, along with their standard deviations (25). The calculated and observed structure factors are ilsted in Figure 4 (25). 
Table 6. Final fractional coordinates for nonhydrogen atoms of compound $\underline{2}^{a}$

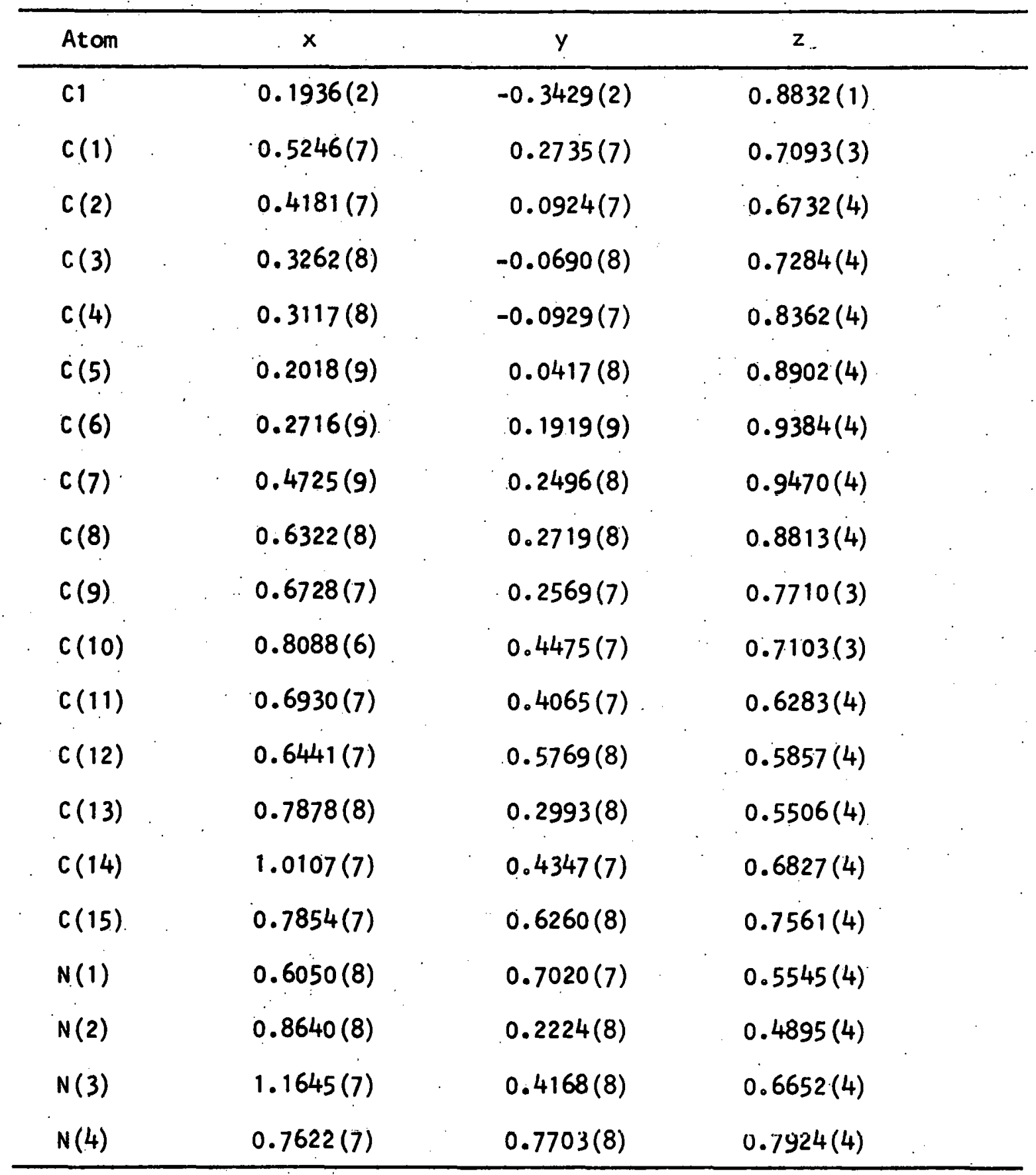

astimated standard deviations, shown in parentheses, are right adjusted to the least significant digit of the preceding number. 
Table 7. Final values of the thermal parameters $\left(\times 10^{4}\right)$ and their standard deviations for compound 2. The form of the temperature factor is $\exp \left(-\beta_{11} h^{2}-\beta_{22} k^{2}-\beta_{33} l^{2}-2 \beta_{12} h k-2 \beta_{13} h l-2 \beta_{23} k l\right)$

\begin{tabular}{|c|c|c|c|c|c|c|}
\hline Atom & $\beta_{11}$ & $\beta_{22}$ & $\beta_{33}$ & $\beta_{12}$ & $\beta_{13}$ & $\beta_{23}$ \\
\hline $\mathrm{Cl}$ & $311(5)$ & $147(3)$ & $65(1)$ & $-53(3)$ & $-61(3)$ & $38(1)$ \\
\hline$c(1)$ & $120(10)$ & $120(10)$ & $36(3)$ & $20(8)$ & $-29(4)$ & $12(4)$ \\
\hline$c(2)$ & $160(10)$ & $160(10)$ & $43(3)$ & $-18(9)$ & $-37(5)$ & $4(5)$ \\
\hline$c(3)$ & $170(10)$ & $140(10)$ & $49(3)$ & $-10(10)$ & $-34(5)$ & $8(5)$ \\
\hline$C(4)$ & $170(10)$ & $130(10)$ & $50(3)$ & $-7(9)$ & $-15(5)$ & $23(5)$ \\
\hline$c(5)$ & $220(10)$ & $160(10)$ & $49(4)$ & $30(10)$ & $-11(6)$ & $30(5)$ \\
\hline$c(6)$ & $260(20)$ & $180(10)$ & $41(3)$ & $20(10)$ & $-11(6)$ & $17(6)$ \\
\hline$c(7)$ & $300(20)$ & $140(10)$ & $39(3)$ & $0(10)$ & $-32(6)$ & $5(5)$ \\
\hline$c(8)$ & $220(10)$ & $160(20)$ & $36(3)$ & $10(10)$ & $-28(6)$ & $16(5)$ \\
\hline$c(9)$ & $120(10)$ & $140(10)$ & $36(3)$ & $-26(8)$ & $-33(4)$ & $24(4)$ \\
\hline$C(10)$ & $93(9)$ & $140(10)$ & $35(3)$ & $21(8)$ & $-22(4)$ & $10(4)$ \\
\hline$c(11)$ & $120(10)$ & $140(10)$ & $37(3)$ & $0(9)$ & $-28(4)$ & $21(5)$ \\
\hline$c(12)$ & $130(10)$ & $160(10)$ & $37(10)$ & $18(9)$ & $-23(4)$ & $12(5)$ \\
\hline$c(13)$ & $160(10)$ & $150(10)$ & $34(3)$ & $18(9)$ & $-20(5)$ & $8(5)$ \\
\hline$c(14)$ & $130(10)$ & $150(10)$ & $48(3)$ & $8(9)$ & $-28(5)$ & $8(5)$ \\
\hline$c(15)$ & $130(10)$ & $180(10)$ & $41(3)$ & $9(9)$ & $-20(5)$ & $15(5)$ \\
\hline$N(1)$ & $260(10)$ & $220(10)$ & $56(3)$ & $90(10)$ & $-38(5)$ & $13(5)$ \\
\hline$N(2)$ & $260(10)$ & $290(20)$ & $50(3)$ & $80(10)$ & $-26(5)$ & $-15(6)$ \\
\hline$N(3)$ & $170(10)$ & $250(10)$ & $74(4)$ & $57(9)$ & $-50(5)$ & $-5(6)$ \\
\hline$N(4)$ & $250(10)$ & $190(10)$ & $63(3)$ & $60(3)$ & $-39(5)$ & $23(5)$ \\
\hline
\end{tabular}


Figure 4. Comparisons of the observed and calculated structure factors (in electrons $\times 10$ ) for 2 


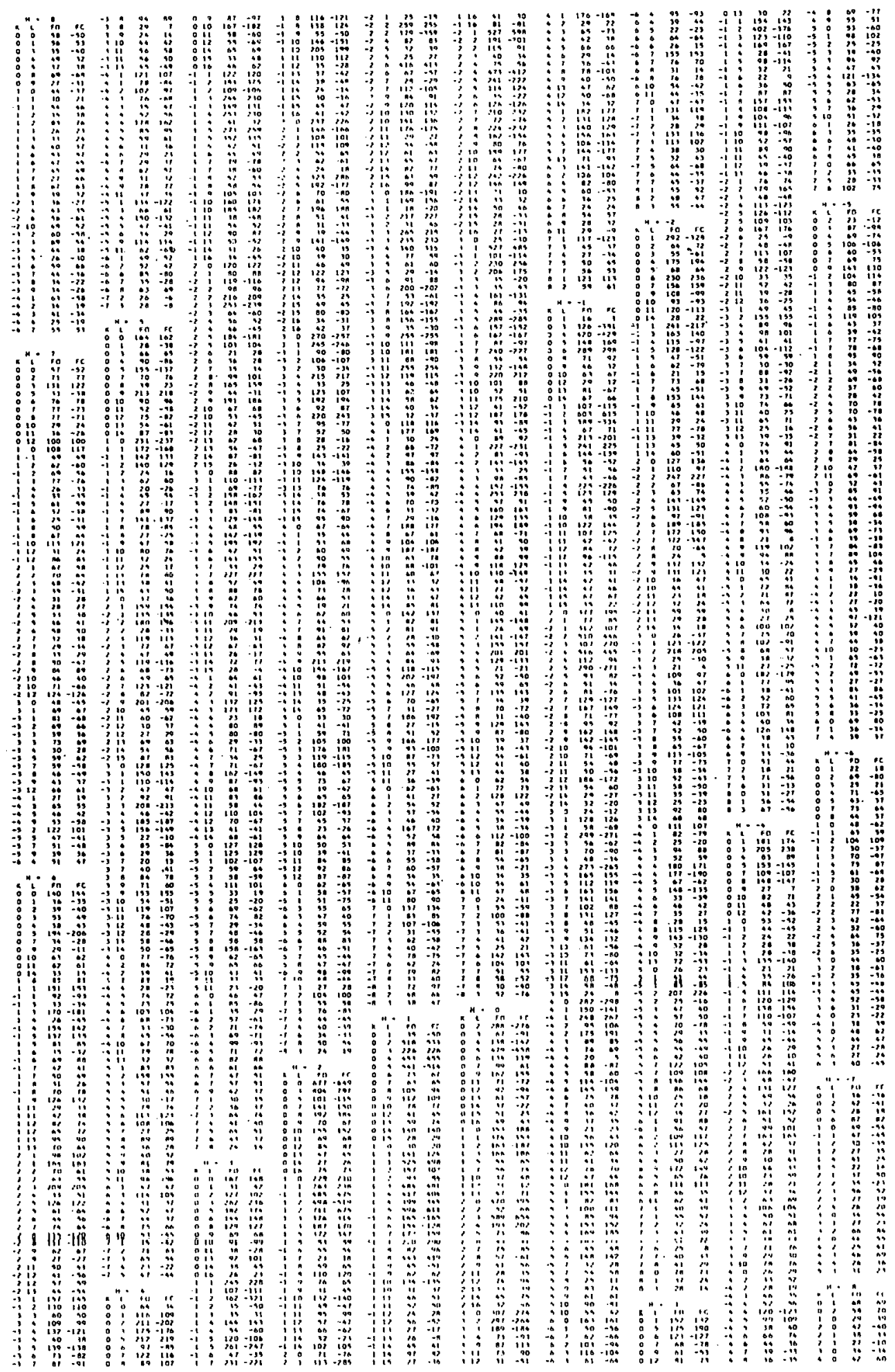


Description and Discussion of Structure

The geometrical configuration of $\underline{2}$ is illustrated in Figure 5 (26). The figure distinctly shows the trans fusion of the four and nine membered rings. The hydrogen atoms on $C(1)$ and $C(4)$ are al so trans disposed. Puckering of the cyclobutyl ring is evident with a $c(1)-c(11)-c(10)-c(9)$ dihedral angle of $19^{\circ}$. Bond lengths for the cyclobutyl ring are long (varying from $1.57-1.59 \AA$ ) indlcating the strain within the ring (27). The dihedral angle for the butadiene segment $C(5)-C(8)$ is $47^{\circ}$. Most bond distances and angles agree well with accepted values. Figure 6 shows the unit cell drawing of the two centrosymmetrically related molecules (26). Tables 8 and 9 list the bond. distances and angles, respectively, along with their deviations (28). Selected dihedral angles are shown in Table 10. 
Figure 5. A computer generated perspective drawing of $\underline{\mathbf{2}}$ 


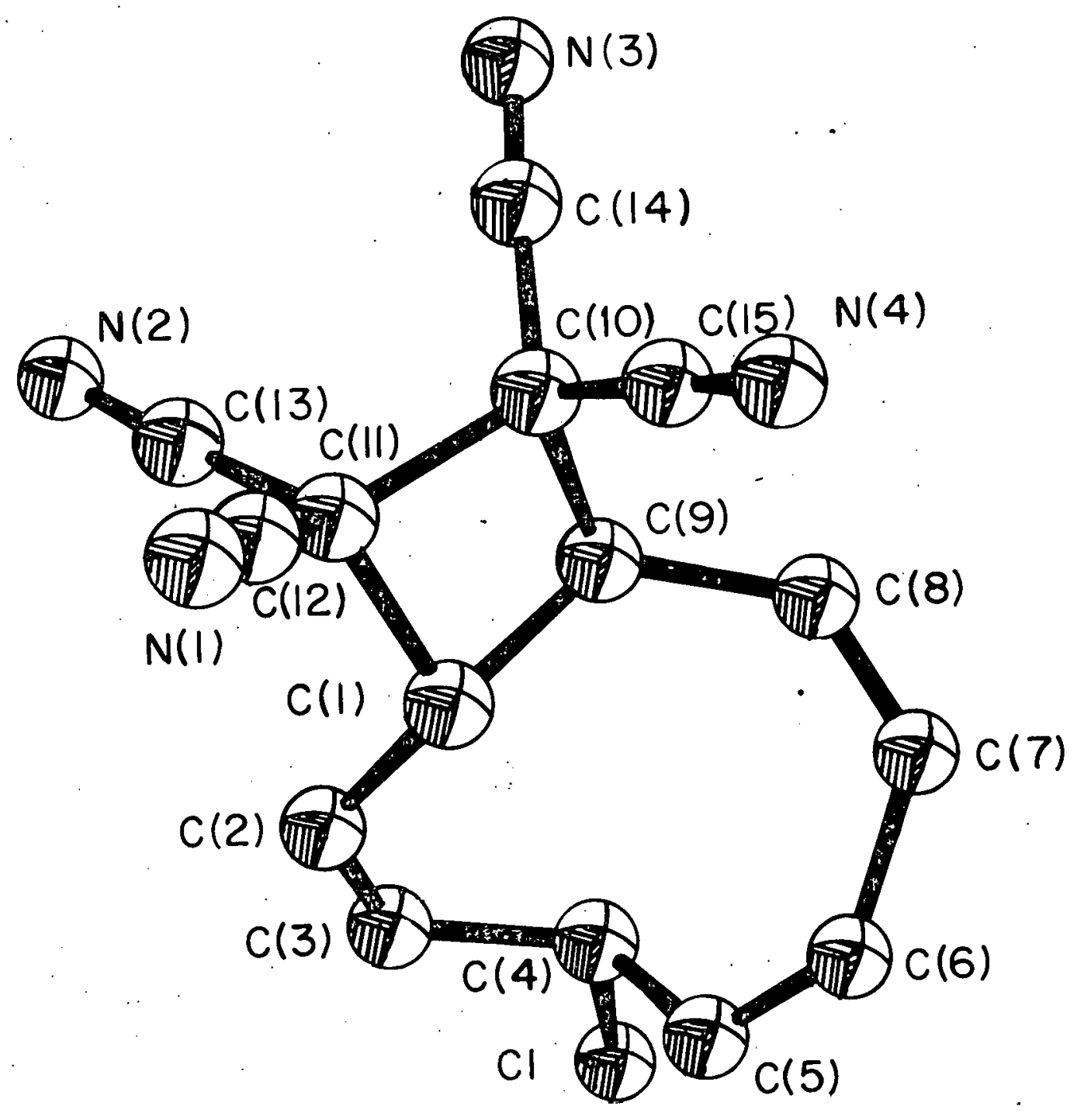


Figure 6. A. computer generated perspective drawing of the unit cell of $\underline{2}$. A is the reference molecu?e at $(x, y, z)$ and $B$ is the centrosymetrically related molecule at $(\bar{x}, \bar{y}, \bar{z})$ 


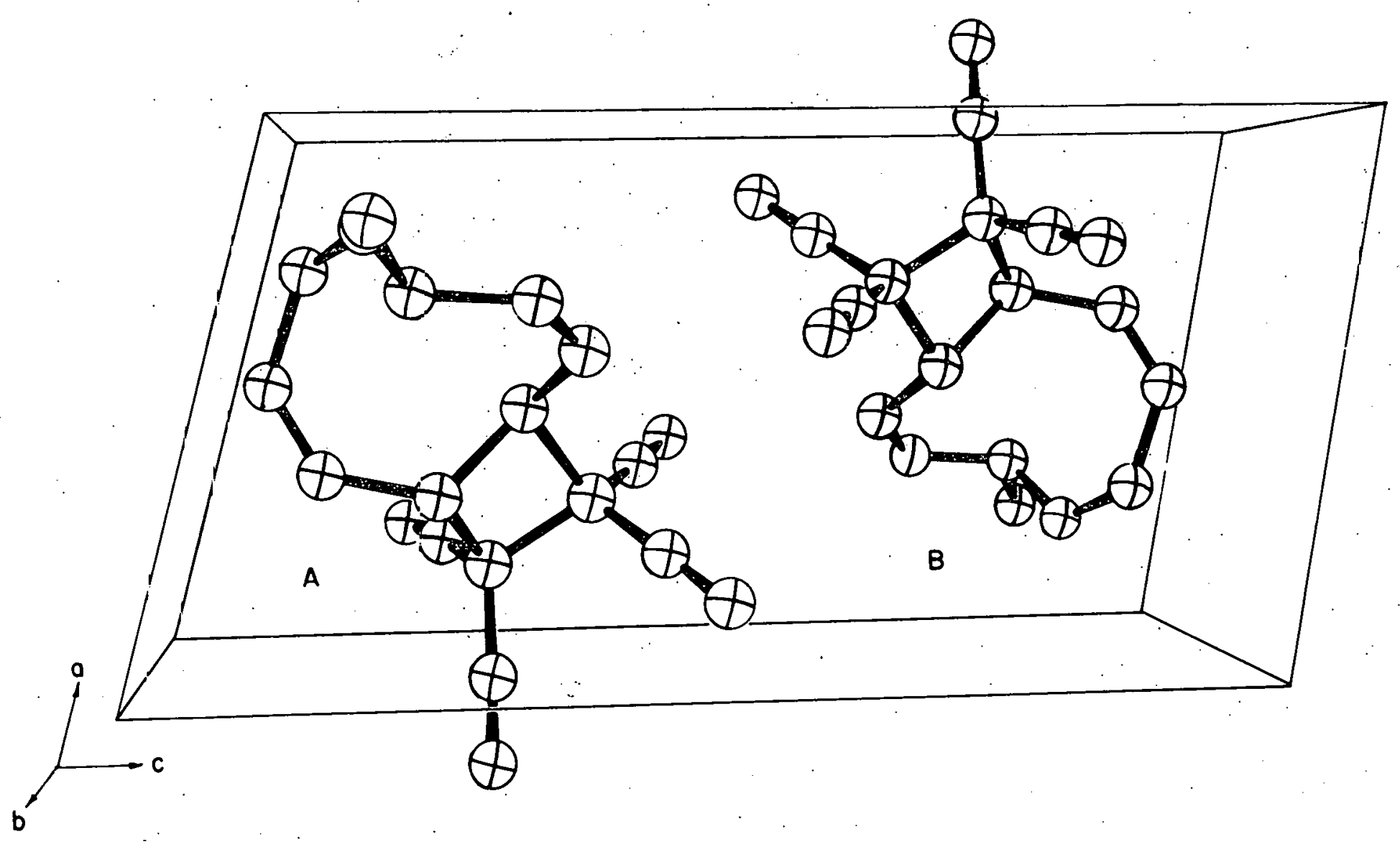


Table 8. Selected bond lengths ${ }^{a}$ for $\underline{2}$

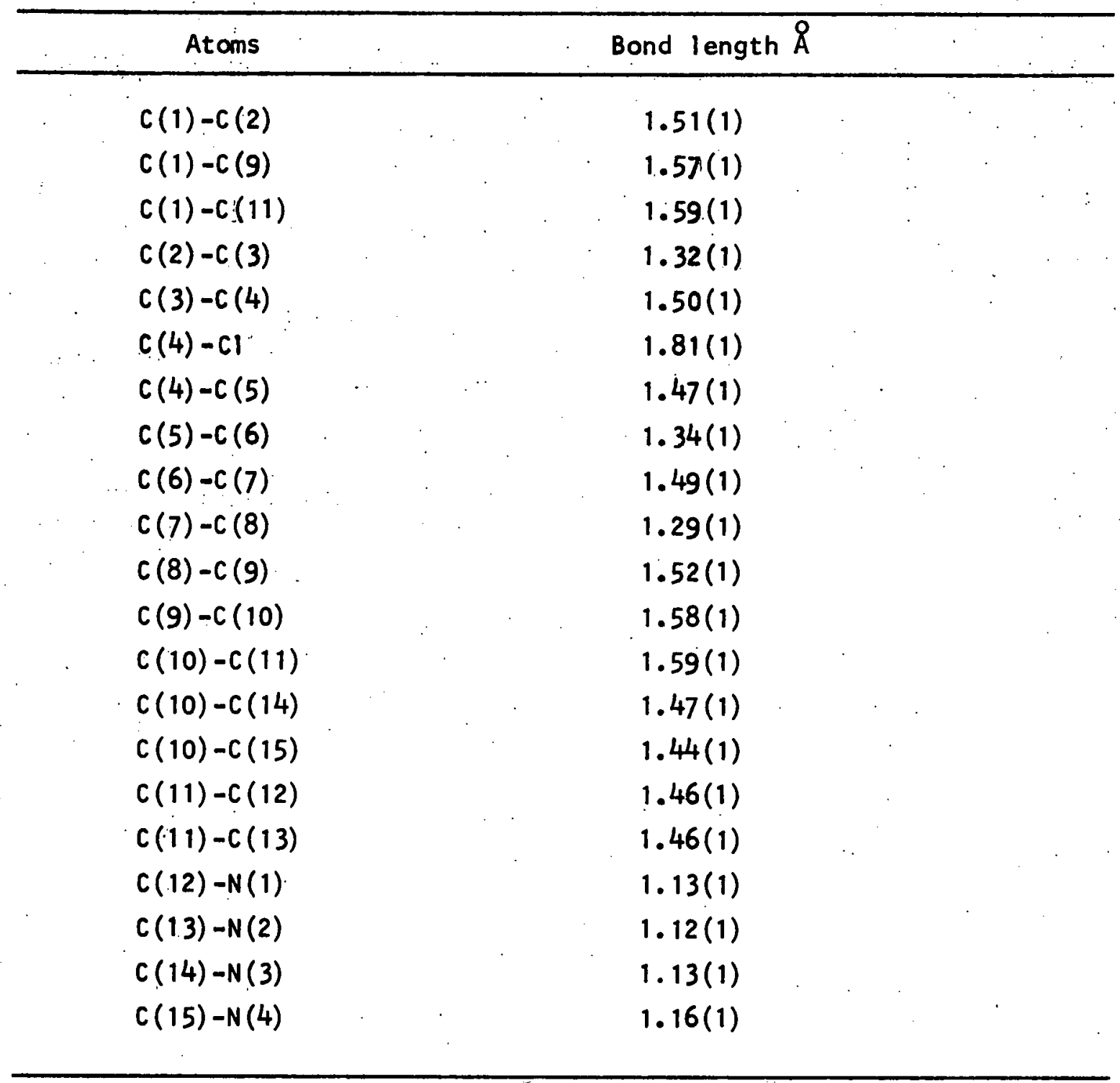

a The estimated standard deviation is given in parentheses for the least significant figure. 
Table 9. Selected interatomic angles ${ }^{a}$ for $\underline{2}$

\begin{tabular}{|c|c|c|c|}
\hline Atoms & Angle, degrees & Atoms & Angle, degrees \\
\hline$c(1)-c(2)-c(9)$ & $121(1)$ & $C(9)-C(10)-c(14)$ & $113(1)$ \\
\hline$c(2)-c(1)-c(11)$ & $115(1)$ & $C(9)-C(10)-C(15)$ & $113(1)$ \\
\hline$c(9)-c(1)-c(11)$ & $88(1)$ & $c(11)-c(10)-c(14)$ & $117(1)$ \\
\hline$c(1)-c(2)-c(3)$ & $124(1)$ & $c(11)-c(10)-c(15)$ & $112(1)$ \\
\hline$c(2)-c(3)-c(4)$ & $123(1)$ & $C(14)-c(10)-c(15)$ & $111(1)$ \\
\hline$c(3)-c(4)-c(5)$ & $111(1)$ & $C(1)-c(11)-c(10)$ & $88(1)$ \\
\hline$c(3)-c(4)-c 1$ & $110(1)$ & $C(1)-C(11)-C(12)$ & $115(1)$ \\
\hline$c 1-c(4)-c(5)$ & $109(1)$ & $C(1)-C(11)-C(13)$ & $115(1)$ \\
\hline$c(4)-c(5)-c(6)$ & $126(1)$ & $C(10)-C(11)-C(12)$ & $116(1)$ \\
\hline$c(5)-c(6)-c(7)$ & $126(1)$ & $c(10)-c(11)-c(13)$ & $111(1)$ \\
\hline$c(6)-c(7)-c(8)$ & $131(1)$ & $c(12)-c(11)-c(13)$ & $117(1)$ \\
\hline$c(7)-c(8)-c(9)$ & $131(1)$ & $C(11)-C(12)-N(1)$ & $179(1)$ \\
\hline$c(8)-c(9)-c(10)$ & $114(1)$ & $C(11)-C(13)-N(2)$ & $.178(1)$ \\
\hline$c(1)-c(9)-c(8)$ & $123(1)$ & $C(10)-C(14)-N(3)$ & $177(1)$ \\
\hline$c(1)-c(9)-c(10)$ & $89(1)$ & $C(10)-C(15)-N(4)$ & $178(1)$ \\
\hline$c(9)-c(10)-c(11)$ & $88(1)$ & & \\
\hline
\end{tabular}

${ }^{\text {a }}$ The est imated standard deviation is given in parentheses for the least significant figure and is calculated from the inverse matrix of least squares refinement. 
Table 10. Selected dihedral angles of $\underline{2} \ldots$

\begin{tabular}{cc}
\hline Atoms & Angle, degrees \\
\hline$c(1)-c(9)-c(10)-c(11)$ & $18^{\circ}$ \\
$c(9)-c(10)-c(11)-c(1)$ & $19^{\circ}$ \\
$c(10)-c(11)-c(1)-c(9)$ & $19^{\circ}$ \\
$c(11)-c(1)-c(9)-c(10)$ & $18^{\circ}$ \\
$c(9)-c(8)-c(7)-c(6)$ & $3^{\circ}$ \\
$c(7)-c(6)-c(5)-c(4)$ & $0^{\circ}$ \\
$c(1)-c(2)-c(3)-c(4)$ & $1^{\circ}$ \\
$c(2)-c(1)-c(9)-c(8)$ & $76^{\circ}$ \\
$c(5)-c(6)-c(7)-c(8)$ & $47^{\circ}$ \\
\hline
\end{tabular}


DISCUSSION OF RESULTS

As was discovered in the structure determinations of $\underline{1}$ and $\underline{2}$, the ring juncture of the four and nine membered rings in both cases was trans. This trans disposition of the hydrogen atoms on carbon atoms $c_{1}$ and $c_{4}$ in 2 supports the mechanistic scheme involving the trans-1,3bishomotropylium ion intermediate advanced by Paquette et al. (15). To follow such a scheme where initial bonding of the electrophile to $C_{3}$ would occur in an exo fashion with readjustment to a trans-1,3-bishomotropylium ion; Clardy et al. (29) suggested that TCNE acted as a dipolar electrophile (Equation 12). The ionic character of TCNE in cycloaddition reactions has been manifest for a variety of systems $(30,31)$.
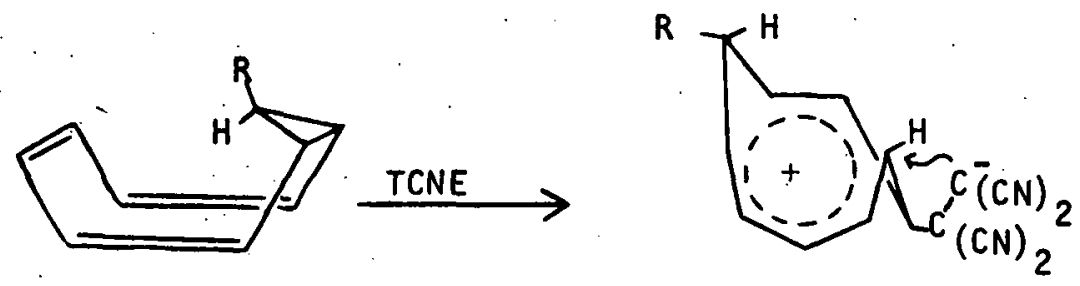

Clardy et al. (29) also stated that the 9-methyl derivative of bicyclononatriene reacted with TCNE to give a compound similar to $\underline{2}$ with respect to nmr data in $69 \%$ yleld, although crystals suitable for $X$-ray structure analysis could not be obtained.

In summary, the crystal structures of 1 and $\underline{2}$ support a mechanistic scheme which involves a trans-1,3-bishomotropylium ion intermediate (29). The negative control experiments of Baxter and Garratt (14) rule out the possibility of a concerted $\left(\pi^{2} s+\pi^{2} s\right)$ cycloaddition of TCNE to cis ${ }^{4}$-cyclononatetraene, and the concerted $\left(\pi^{2} a+\pi^{2} s\right)$ reaction of $\underline{c i s}{ }^{2}$, trans, 
c.is-cyclononatetraene would lead exclusively to cis ring fusion in the adduct. Also, because of the stereoselectivity at $\mathrm{C}_{4}$ in $\underline{2}$, the postulation of stepwise $\pi^{2}+\pi^{2}$ cycloaddition to cis ${ }^{2}$, trans, cis-bicyclononatetraene can be rejected (29). The results obtained also contradict Warner and Winstein's (19) proposal that the 1,3-bishomotropylium ion intermediate evolving from electrophilic addition to bicyclo[6.1.0]nona2,4,6-triene has cis disposed methylene bridges.

In conclusion, a question may now be posed as to why the TCNE cycloaddition to the 9-chloro and 9-methyl derivatives of bicyclononatriene lead to two different major products. In the 9-chloro derivative reaction with TCNE the main product is compound 18 , while the 9-methyl derivative reaction with TCNE leads to a compound with characteristics similar to compound $\underline{2}$ which is a minor product of the 9 -chloro derivative reaction. Further mechanistic studies would be of interest in solving this question. 
BIBLIOGRAPHY

1. E. Vogel, Angew. Chem., 23, 548 (1961); H. Kiefer, Dissertation, Köln, 1962.

2. E. Vogel, Angew. Chem., 24; 829 (1962); Angew. Chem., Int. Ed. Engl., 2, 1 (1963).

3. T. J. Katz and P. J. Garratt, J. Amer. Chem. Soc., 86, 5194 (1964).

4. E. A. La Lancette and R. E. Benson, J. Amer. Chem. Soc., 1941 (1965).

5. J. C. Barborak, T. M. Su, P. V. R. Schleyer, G. Boche, and

G. Schnelder, J. Amer. Chem. Soc., 23, 279 (1971).

6. R. B. Woodward and R. Hoffmann, Angew. Chem., Int. Ed. Engl., ' , 781 (1969).

7. P. V. R. Schleyer, T. M. Su, M. Saunders; and J. C. Rosenfeld, J. Amer. Chem. Soc., 21, 5174 (1969).

8. S. W. Staley and T. J. Henry, J. Amer. Chem. Soc., 21, 1239 (1969).

9. S. W. Staley and T: J. Henry, J. Amer. Chem. Soc., 21, 7787 (1969).

10. A. G. Anastassiou and R. C. Griffith, J. Amer. Chem. Soc., 23, 3083 (1971).

11. B. K. Bullimore, J. F. W. McOmle, A. B. Turner, M. N. Galbralth, and W. B. Whaley, J. Chem. Soc. C, 1289 (1967).

12. W. Steglich and W. Reininger, Chem. Comm., 178 (1970).

13. W. H. Okamura and T. W. Osborn, J. Amer. Chem. Soc., 22,1061 (1970).

14. C. S. Baxter and P. J. Garratt, J. Amer. Chem. Soc., 92, 1062 (1970).

15. L. A. Paquette, M. J. Broadhurst, C. M. Lee, and J. C. Clardy, J. Amer. Chem. Soc., 24,630 (1972).

16. L. A. Paquette and M. J. Broadhurst, J. Amer. Chem. Soc., 24,632 (1972).

17. J. C. Martin and B. R. Ree, J. Amer. Chem. Soc., 21, 5882 (1969);

J. Amer. Chem. Suc., 22, 1660 (1970).

18. P. Schleyer and V. Bass, J. Amer. Chem. Soc., 21, 5880 (1969). 
19. P. Warner and S. Winstein, j. Amer. Chem. Soc., 23, 1284 (1971).

20. D. E. Williams and R. E. Rundle, J. Amer: Chem. Soc., 86, 1660 (1964).

21. A. J. C. Wilson, Nature, 150, 152.(1964); J. Karle and H. Hauptman, Acta Cryst.; 2, $635(1956)$.

22. R. E. Long; Ph.D. Thesls, Univ. of California at Los Angles, 1965.

23. C. R. Hubbard, C. O. Quicksall, and R. A. Jacobson, "The Fast Fourler Algorlthm and Programs ALFF, ALFFDP, ALFFPROJ, ALFFT, and FRIEDEL," U. S. Atomic Energy Commission Report IS-2625, lowa State Univ., Ames Institute for Atomic Research, 1971.

24. H. P. Hanson, F. Herman, J. D. Lea, and S. Skillman, Acta Cryst, 17 , 1040 (1967).

25. W. R. Busing, K. O. Martin, and H. A. Levy, "A Fortran Crystallographic Least-Squares Programs," U. S. Atomic Energy Commission Report ORNL-TM-305, Oak Ridge National Laboratory, Tenn., 1965.

26. C. K. Johnson, "ORTEP, A Fortran Thermal-Ellipsoid Plot Program For Crystal Structure Illustrations,"U. S. Atomic Energy Commission Report ORNL-3794, Oak Ridge National Laboratory, Tenn., 1965.

27. J. D. Dunitz, Acta Cryst., 2, 1 (1969).

28. W. R. Busing, K. O. Martin, and H. A. Levy, "A Fortran Crystallographic Function and Error Program," U. S. Atomic Energy Commission Report ORNL-TM-306, Oak Ridge National Laboratory, Tenn., 1964.

29. J. Clardy, L. K. Read, M. J. Broadhurst, and L. A. Paquette, J. Amer. Chem. Soc., 24, 2904 (1972).

30. P. D. Bartlett, Quart. Rev. Chem. Soc., 24, 473 (1970).

31. J. E. Baldwin and R. K. Pinschmidt, Jr., Tetrahedron Lett.; 935 (1.971). 


\section{ACKNOWLEDGEMENT}

At this time, the author would like to express his sincere indebtedness to Dr. Jon C. Clardy. His patience, knowledge, and conscientious guidance helped the author to mature as a chemist and a person.

Much appreciation and gratitude is also owed to all the members of X-ray groups I and II for their assistance.

The author would like to thank his parents for their understanding and faith while he continues his graduate training. 